\title{
Retrospective Analysis of US LWR Technology Commercialization: Lessons for Today's Nuclear Industry
}

Jason K Hansen, Brent W Dixon, Arantxa Cuadra-Gascon, Michael Todosow, Aditi Verma

May 2020

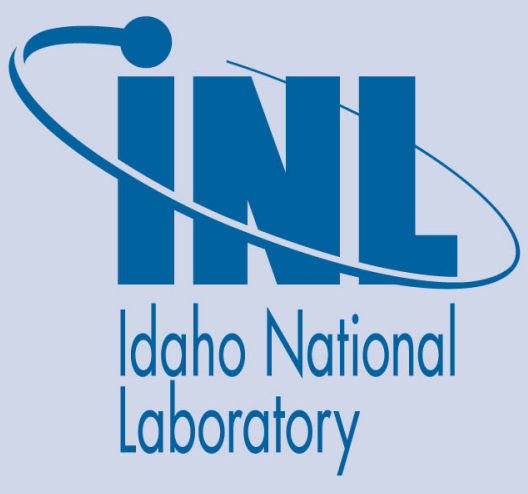

The INL is a U.S. Department of Energy National Laboratory operated by Battelle Energy Alliance 


\title{
Retrospective Analysis of US LWR Technology Commercialization: Lessons for Today's Nuclear Industry
}

\author{
Jason K Hansen, Brent W Dixon, Arantxa Cuadra-Gascon, Michael Todosow, \\ Aditi Verma
}

May 2020

Idaho National Laboratory Idaho Falls, Idaho 83415

http://www.inl.gov

Prepared for the

U.S. Department of Energy

Under DOE Idaho Operations Office

Contract DE-AC07-05ID14517 


\section{RETROSPECTIVE ANALYSIS OF US LWR TECHNOLOGY COMMERCIALIZATION: \\ LESSONS FOR TODAY'S -NUCLEAR INDUSTRY Nuclear Fuel Cycle and Supply Chain}






\section{DISCLAIMER}

This information was prepared as an account of work sponsored by an agency of the U.S. Government. Neither the U.S. Government nor any agency thereof, nor any of their employees, makes any warranty, expressed or implied, or assumes any legal liability or responsibility for the accuracy, completeness, or usefulness, of any information, apparatus, product, or process disclosed, or represents that its use would not infringe privately owned rights. References herein to any specific commercial product, process, or service by trade name, trademark, manufacturer, or otherwise, does not necessarily constitute or imply its endorsement, recommendation, or favoring by the U.S. Government or any agency thereof. The views and opinions of authors expressed herein do not necessarily state or reflect those of the U.S. Government or any agency thereof. 


\section{Executive Summary}

The nuclear industry today is at a hinge point, defined by characteristics not unlike what the industry faced in earlier eras. There are issues standing in the way of straightforward deployment of advanced reactors and new nuclear concepts. Summarized, these include issues that are related to technical safety and licensing; safeguards, security, and proliferation; factors in the economic environment; public perception; and issues that prevent the on-time and on-budget completion of nuclear projects. To support generating information to guide passage over these industry hurdles, this study focused on the historical events leading up to the successful commercialization of light water reactor (LWR) technologies. ESFigure 1 shows a timeline of these significant events.

The period of commercialization is marked by actions taken by Admiral Rickover in 1945 and runs through the generating stations at Oyster Creek and Ginna in 1969 and 1970. This timeframe is the focus of the study because these two reactor projects were the first large-scale power plants financed exclusively by the private sector. Certainly, much has occurred in the nuclear industry since 1970 but this study aims specifically at the period of commercialization. The events leading up to that point illustrate a back-and-forth relationship between entities of the US Government and corporations in the private sector, a relationship which was key to the successful commercialization of LWR technologies. The relationship is one where financial risk alternated between entities, but the finished product was a technology that in the early 1970s was economically viable on its own merits.

Analyzing the events of this timeline from the lens of current industry barriers, this study reports the following lessons. They shed light on how stakeholders interested in advanced reactors and new nuclear concepts in today's nuclear industry might proceed and successfully get past existing issues.

\section{Lessons to apply in the economic environment}

- LWR technology succeeded because those who promoted it had a defined problem (national security) they were seeking to solve. The technology was 'pulled' into development to solve a problem then 'pushed' into another area (civilian power) where it created value.

- Industry investment in new technology is proportional to the expected payoffs from the investment and the perceived risks; this economic principle presents itself in actions of early corporate involvement in the nuclear industry.

- First-movers in an industry bear risks that generate positive externalities for firms that follow. The role of the "Government" in bringing a new technology to market is to offset first-mover risks.

- Technology adoption depends on faster movement along the learning curve, relative to competition. The more that is known about a technology early in its development, the more that technology edges out new entrant technologies for which less is known.

\section{Lessons to apply in current policy and regulation - Government Role}

- Capacity to regulate civilian power in the US developed alongside of LWR technology itself; development in regulation goes hand-in-hand with development in technology.

- Policy support is a function of public perception; policies reflect majority of public perception. When public opinion rallies around a central issue of concern then policies reflect that issue.

- Because of the important role of learning in technology adoption, new knowledge should be captured and shared in a way that others generating new technology can apply it.

- Down-select leads to technology "lock-in” but lock-in is in fact necessary for industry progress. 
- Congressional support, like that gaining traction today in the Advanced Reactor Demonstration Program, is not without precedent, it was instrumental for initial development.

\section{Lessons to apply in marketing developing technologies internationally}

- With respect to exporting nuclear technology, domestic manufacturers should negotiate localization and technology transfers in the technology sale.

- The diffuse ownership of reactor companies in the past may suggest that emerging new designers and developers of advanced reactors may want to consider a similar approach of cultivating mutually beneficial partnerships with countries and organizations to which they transfer their technologies.

Recently, a working group focused on the nuclear fuel cycle in the US published an important strategy document (DOE 2020). The working group outlined key steps for the US Government to take to shore-up the nuclear industry in the country. Many of these recommended actions have historical context in the buildup of the LWR technology. This lessons-learned study describes the relevant history that supports the working group document, which mapped the important link in national security and a robust nuclear industry. The US experienced a similar sentiment in 1949 when the then Soviet Union detonated its first atomic bomb. That event propelled the US nuclear industry forward, including an important presidential speech titled "Atoms for Peace" and a civilian reactor program leading to the Shippingport generating station. This lessons-learned document describes how that sentiment impacted growth in LWR technology. The working group document called out an important reality with historical precedence. It says, (DOE 2020, 10),

"The scale of these challenges indicate that a defense-only perspective fails to provide economies of scale to stimulate sufficient demand to protect US national security interests."

This statement reflects the driving force behind the build-up of the civilian nuclear industry in the US, which this lessons-learned document describes. Nuclear power for electricity generation was not the primary purpose leading to the technology's development, but it was a primary driver for maintaining an industrial base sufficiently robust to support military applications of nuclear technology.

This lessons-learned study reports this and many other lessons relevant for today's industry. 


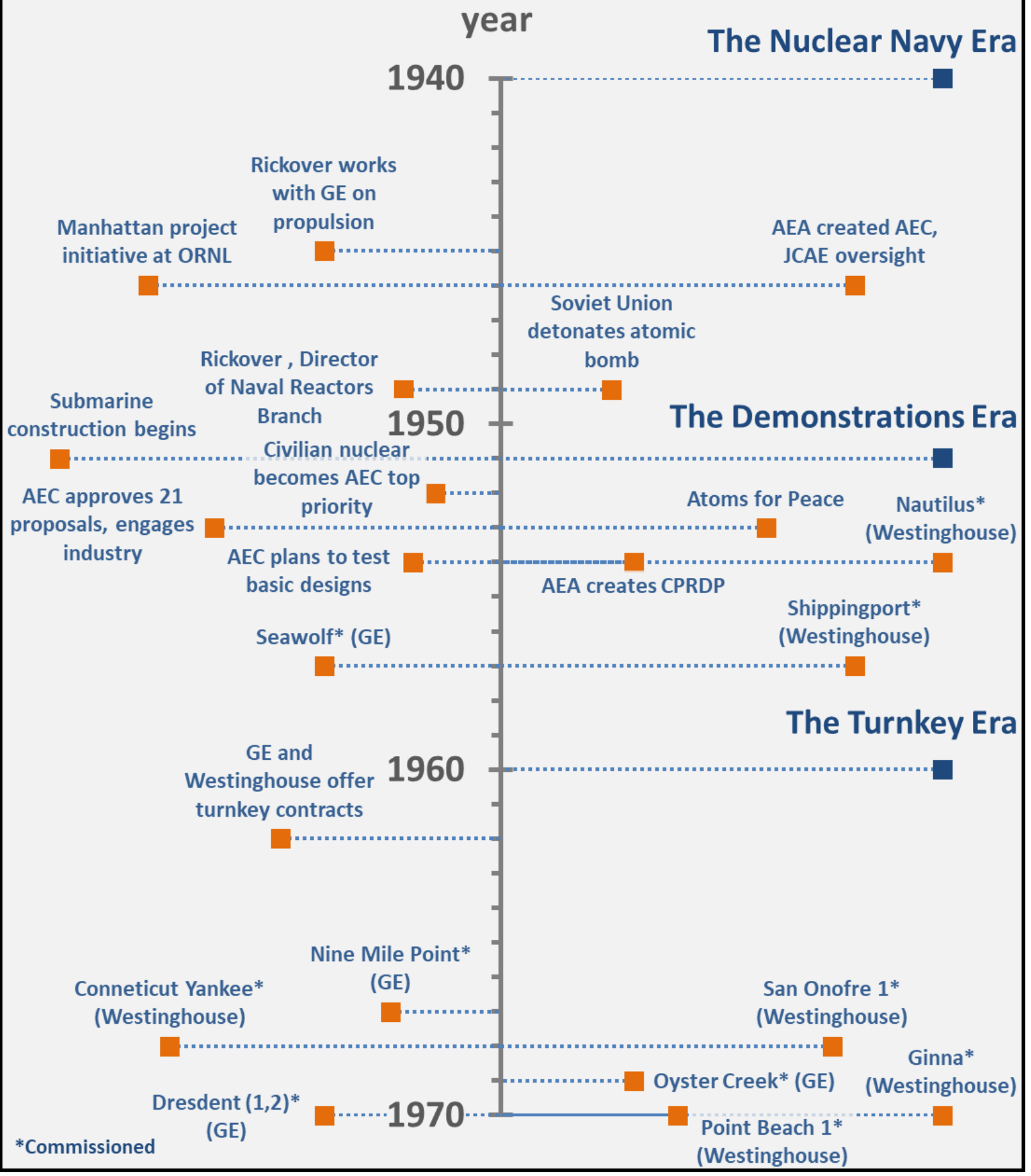

ES-Figure 1 LWR Timeline to Commercialization 


\section{Acknowledgement}

The authors would like to thank Dr. David Diamond and Dr. Lap-Yan Cheng, both from BNL, for valuable feedback on earlier drafts. The authors also wish to thank Dr. Temi Taiwo, Dr. T.K. Kim and Dr. Bill Halsey from ANL, David Shropshire from INL and Dr. Sama Bilbao Y Leon from NEA for helpful comments provided during the document review. 


\section{Contents}

Executive Summary.

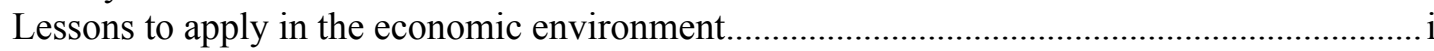

Lessons to apply in current policy and regulation - Government Role.................................... i

Lessons to apply in marketing developing technologies internationally.................................. ii

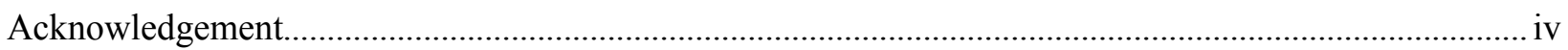

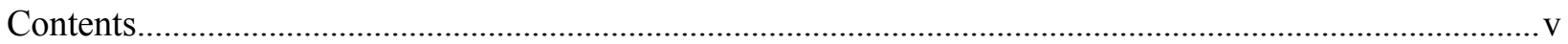

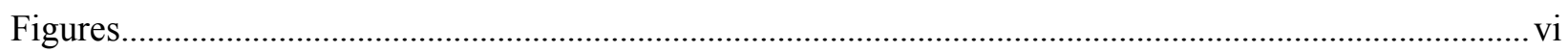

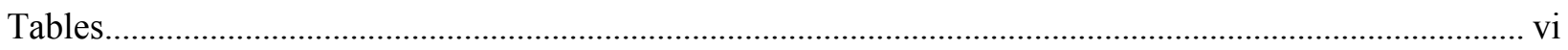

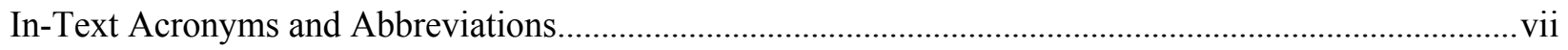

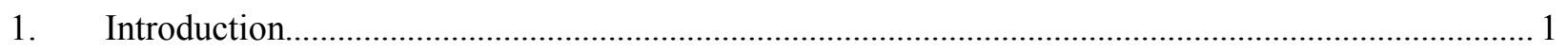

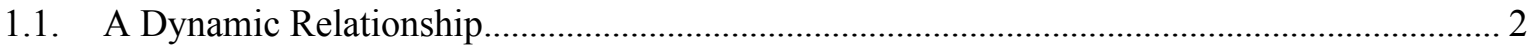

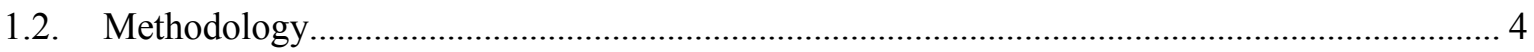

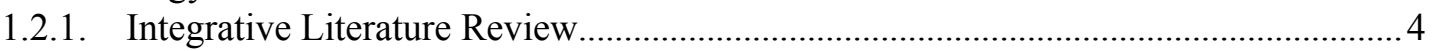

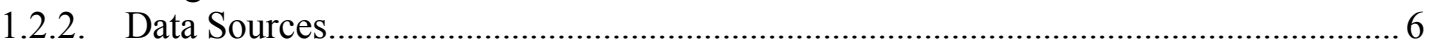

2. Growth in LWR Technology: Development, Deployment and Diffusion.......................................... 7



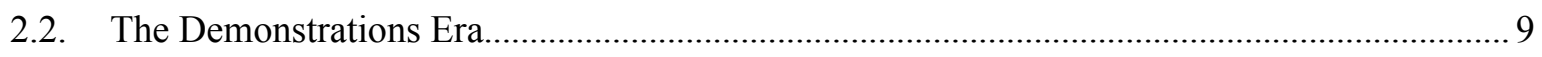

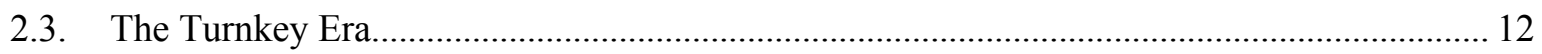

2.4. Role of International Engagement.................................................................................. 18

2.4.1. Securing market dominance through technology transfer, localization, and

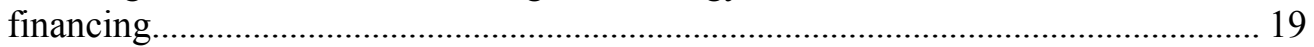

2.4.2. Diffuse ownership and longevity of reactor companies............................................ 20

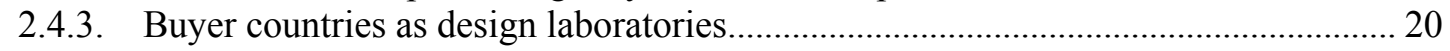

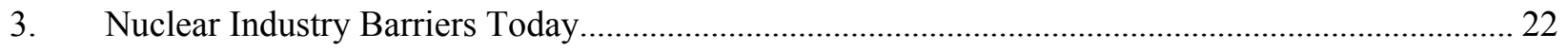

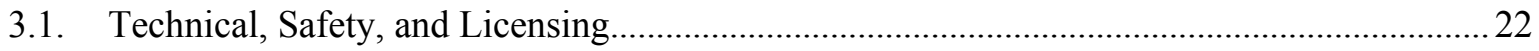



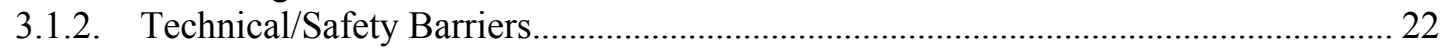

3.2. Safeguards, Security and Proliferation-related Barriers......................................................23



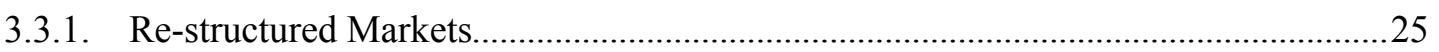

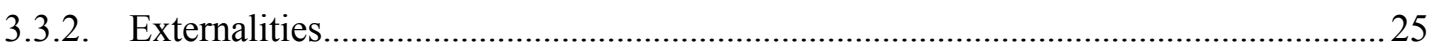

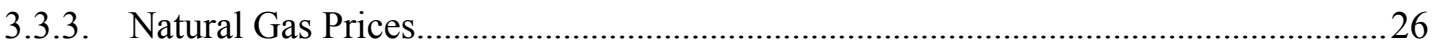

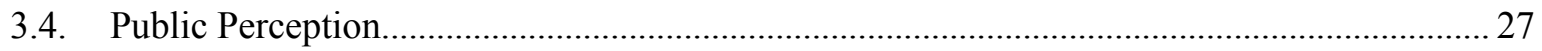

3.5. Barriers to On Time and On Budget Project Completion..................................................... 28

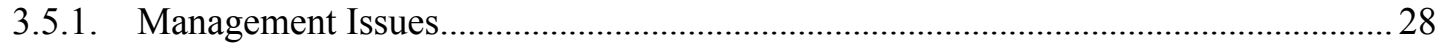

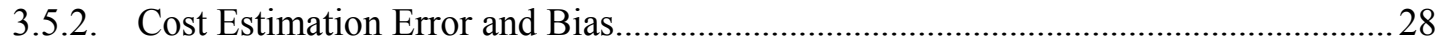

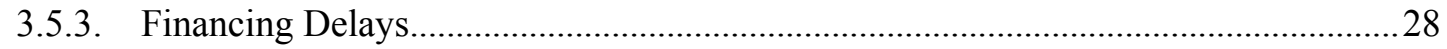




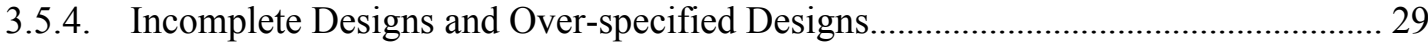

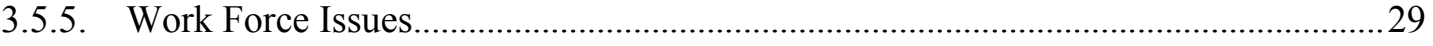

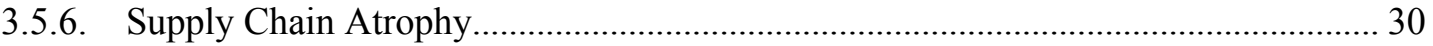

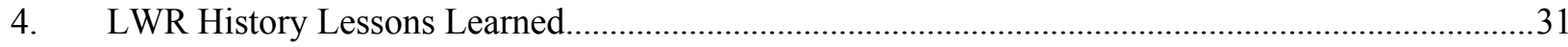

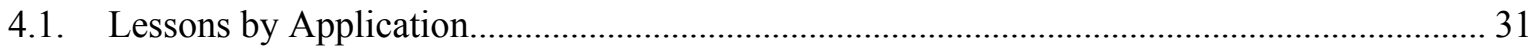

4.1.1. Lessons to Apply in the Economic Environment.........................................................

4.1.2. Lessons to Apply in Current Policy and Regulation - Government Role....................31

4.1.3. Lessons to Apply in Marketing Developing Technologies Internationally..................31

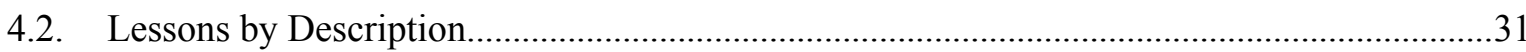

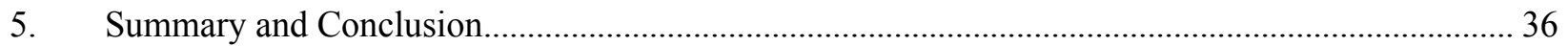

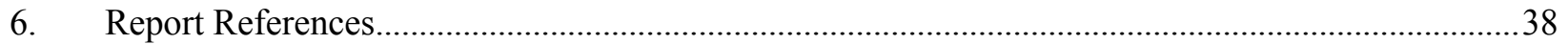

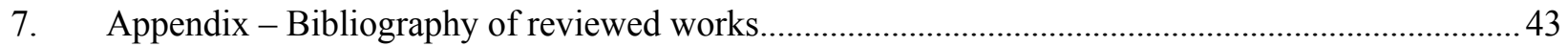

Figures

Figure 1 Causal Loop Diagram of Growth in LWR Technology ............................................................... 3

Figure 2 LWR Timeline to Commercialization.......................................................................................

Figure 3 Expanded Causal Loop Diagram of Growth in LWR Technology................................................. 8

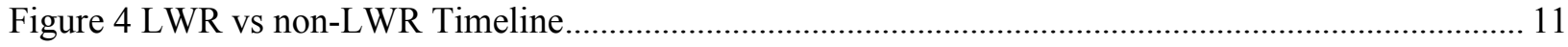

Figure 5 Electricity Market Conditions 1960 - 1980..................................................................................13

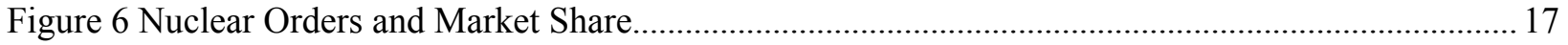

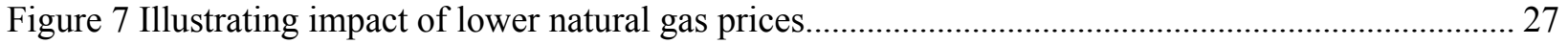

\section{Tables}

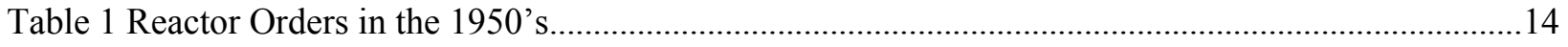

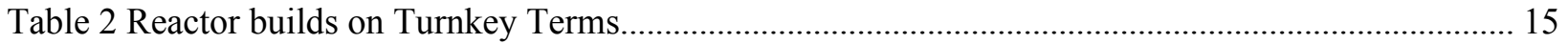




\section{In-Text Acronyms and Abbreviations}

3S safety, security, and safeguards

ABWR Advanced Boiling Water reactor

AEA Atomic Energy Act

AEC Atomic Energy Commission

ANL Argonne National Laboratory

BEA Bureau of Economic Analysis

BNL Brookhaven National Laboratory

BNFL British Nuclear Fuels Ltd

BWR boiling water reactor

BWXT BWX Technologies

CLD causal loop diagram

CRBR Clinch River Breeder Reactor

CRPDP Cooperative Power Reactor Demonstration Program

DOE U.S. Department of Energy

EBWR experimental boiling water reactor

EPR European Pressurized Reactor (GENIII PWR developed by France)

EPRI Electric Power Research Inst

EXIM American Export-Import

FERC Federal Regulatory Commission

FFTF Fast Flux Test Facility
MC\&A material control and accounting

MWe Megawatt electric

MHTGR/ modular high temperature gas-cooled

NGNP reactor/next generation nuclear plant

MIT Massachusetts Institute of Technology

NEA Nuclear Energy Agency

NRC Nuclear Regulatory Commission

NEIMA Nuclear Energy Innovation and Modernization Act

OSTI Office of Science and Technical Information

ORNL Oak Ridge National Laboratory

PR\&PP proliferation resistance and physical protection

PRISM power reactor innovative small module

PWR pressurized water reactor

RAND Research ANd Development

RTO Regional Transmission Office

SBD safeguards-by-design

SHINE SHINE Medical Technologies

SIR submarine intermediate reactor

SMR small modular reactors

SNM special nuclear materials 


\author{
GDP gross domestic product \\ GE General Electric \\ GEH General Electric-Hitachi \\ GIF GEN IV International Forum \\ HEU highly enriched uranium \\ HALEU high assay low enriched uranium \\ HTGR high temperature gas-cooled reactor \\ IAEA International Atomic Energy Agency \\ INL Idaho National Laboratory \\ IPP Industrial Participation Program \\ JCAE Joint Committee on Atomic Energy \\ LMFR liquid metal fast reactor \\ LOCA loss-of-coolant-accidents \\ LWBR Light-Water Breeder Reactor \\ LWR light water reactor
}

STR Submarine Thermal Reactor Mark I

S1G Land-based prototype

S2G Marine-based reactor

S1W STR renamed

S2W Submarine Thermal Reactor Mark II

TRISO tristructural-isotropic fuel

TVA Tennessee Valley Authority

UK United Kingdom

US United States

West Westinghouse

WNA World Nuclear Association

WPPSS Washington Public Power Supply System

USD United States Dollars 


\section{Retrospective analysis of US LWR technology commercialization: Lessons for today's nuclear industry}

\section{Introduction}

The purpose of this study is to investigate the development, innovation and diffusion of light water reactor (LWR) technologies in the United States (US) over the timeframe of commercialization; that is, the period from government funded LWR development to the point where capital investment from the private sector entirely funded the further commercial implementation and development of LWR concepts $(\sim 1945$ - 1970). As a technology, LWR found success in its domain of initial application, military purposes, but it was also successful outside of its original purpose. It was diffused, i.e. applied outside of military applications, into the market for civilian power generation. It is this combination of successful development, deployment and subsequent diffusion that makes the LWR technology one ideally suited for drawing lessons for the industry today. Non-LWR technologies did not attract the same level of application and are thus not included as a direct field of study in this report. However, they are included to the extent that they contributed to LWR gaining industry dominance. The goal of the study is to generate actionable information for reactor developers, government agencies and private investors based on historical facts relating to LWR development and deployment. Using this history, the analysis generates lessons to help potentially guide the domestic nuclear industry, in terms of advanced concepts and current fleet issues, over existing barriers today.

The path to commercializing LWR technology was not straightforward. It zigzagged between military applications and civilian power production. Then it turned at pivotal points, down-selects, where interested stakeholders faced choosing between nuclear energy technology alternatives. Although several concepts were explored to various degrees in the "early days," the reality is that despite the choices, and for reasons discussed in this report, the LWR prevailed. Understanding these decisions by various entities, the involved stakeholders from government and industry, and their motivating incentives, forms the basis of historical lessons learned that may contribute to development, deployment, and licensing of advanced reactors today. Considering industry barriers today in the context of the LWR history generates insights for potentially addressing today's challenges. This study will make the case that, like the early winding path of LWR commercialization, challenges facing deployment of advanced reactor concepts today are complex and convoluted, but not insurmountable and that looking to history, and learning from it, can help guide the path of new concepts over such challenges, particularly for advanced reactor designs that are now approaching the commercialization phase.

The timeframe for commercializing LWR technology in civilian power production spans the decision to build the Shippingport reactor in 1954, a project with a significant government role, specifically the US Navy, to the startup of the first purely commercial reactors at Ginna and Oyster Creek in 1969 and 1970 (Krahn 2017). For this analysis, the fact that complete, sole financing from the private sector of these two reactors marks the end of the commercializing period. But a lot happened in the LWR history preceding this timeframe that bears on this commercializing outcome. The US Navy earnestly sought nuclear technology development for various systems, eventually focusing on submarines. Firms in industry, particularly Westinghouse and General Electric (GE), actively pursued nuclear technology development, initially based to a large degree on the needs of the US Navy. A partnership, so to speak, emerged between government and industry. And this relationship is central to the success of LWR technology in the US.

Researchers working on this study synthesized information from history to generate approaches for addressing issues facing industry today. Hence, a retrospective analysis enables generating lessons for overcoming barriers. Other researchers have studied the historical development of the nuclear industry in the United Kingdom (Wearne and Bird 2009) and in the US (Finan 2012, Gillespie et al. 2016, Krahn 
2017), offering industry lessons in their own right This study adds to this line of inquiry with a specific contribution; it reviews the salient pieces of the LWR history, focused on the US, for lessons relevant to today's US nuclear industry.

This report proceeds as follows. The remaining part of this section elucidates the key features of the relationship between government and industry as it pertains to the LWR history. Then the section describes the method for evaluating the LWR history and generating lessons. Section 2 discusses three distinct timeframes in the LWR history, relating the progression of LWR technology from the conceptual phase through to an economically viable commercial application of the technology. It also includes the role of early international engagement. Section 3 summarizes the major issues facing the nuclear industry today so that in Section 4 the lessons of history can be applied to current barriers. Section 5 summarizes the report and concludes with suggestions for next steps by identifying opportunities for future research.

\subsection{A Dynamic Relationship}

LWR technology development, deployment and diffusion is a function of a dynamic relationship between stakeholders in government and industry. This encompasses early LWR technology development, its initial deployment to national security applications, and then its diffusion to an alternative use which was not originally intended at technology inception (i.e. the diffusion). Throughout the LWR history, it is this relationship that was key to LWR commercialization. Systematically investigating it illustrates key features for today. On the government side of the relationship, these include military leaders (e.g., Admiral Rickover) and policymakers (e.g., President Dwight D. Eisenhower) while on the industry side these stakeholders include industry leaders from firms such as reactor vendors, architect-engineers, and construction firms (e.g., GE and Westinghouse). The incentives and motivations of these stakeholders must be considered in the context of the specific timeframes wherein their respective interactions, decisions, and outcomes, (e.g., post-World War II and the Cold War), played a role in the LWR history. The success of nuclear energy in the civilian power market is due to the dynamic relationship that developed between these two stakeholder groups. Figure 1 shows a causal loop diagram (CLD) of this relationship, which is an influence diagram. ${ }^{1}$

In Figure 1 "Growth in LWR Technology" is the behavior of interest over time. In this high level CLD, Growth in LWR technology can be thought of as representing two things: the number of times LWR technology was applied, either in military applications or civilian power, and the knowledge development that accrued from repeated application of the technology. The figure shows two reinforcing, positive feedback loops that drive growth. That is, a positive relationship exists between the connected variables in the CLD. Government motivations and actions played a role in growing LWR technology, which the reinforcing loop labeled R1 identifies. And motivations and actions in industry, also, played a role in expanding the technology, hence R2 illustrates industry impact. The CLD begins with the "Demand for National Security" in R1. This can be thought of in two ways: initiatives from the military for nuclear propulsion on US Navy submarines and political initiatives aimed at increasing national security by building an industry around nuclear power in the civilian energy market. At the heart of the role of government lie two central functions: the protective function and the productive function (Gwartney et al.

${ }^{1}$ A CLD is an analytical tool from the discipline of system dynamics that illustrates the cause-and-effect relationships of key variables of a system ((Sterman 2000)) The circular relationship shows how variables of a system interact, either growing or decreasing over time. Arrows indicate the direction of the casual relationship. The interpretation, for example, of an arrow originating on " $\mathrm{X}$ " and ending on " $\mathrm{Y}$ " means that $\mathrm{X}$ causes $\mathrm{Y}$ to increase or decrease above what it would have if $\mathrm{X}$ had not changed. When signs are attached to the arrows (+/-) they indicate how Y changes due to changes from X. CLD aid in identifying the feedback loops in a system and variables that drive system behavior. 
2018). As this report presents the development, deployment, and diffusion of LWR technology, the reader will see how the US government's demand for national security drove government investment in technology development, hence the positive relationship between the two in the CLD. This investment in new technology created a "demand-pull" where the investment pulls technology development along then funds technology deployment. The government demand for LWR technology on Navy submarines pulled LWR technology along until the industry loop kicked in. Industry was involved in government efforts to develop and deploy LWR technology. But the government's demand-pull remained the primary driver of LWR growth, beginning in the mid 1940's, through to the time when industry investments completed technology maturation to the point where government financing was no longer necessary for investments in LWR. The two positive feedback loops, then, worked together to drive LWR technology growth until near the end of the 1960's, a period commonly called "The Turnkey Era." (See Figure 2 for the events underlying the concepts in this CLD.)

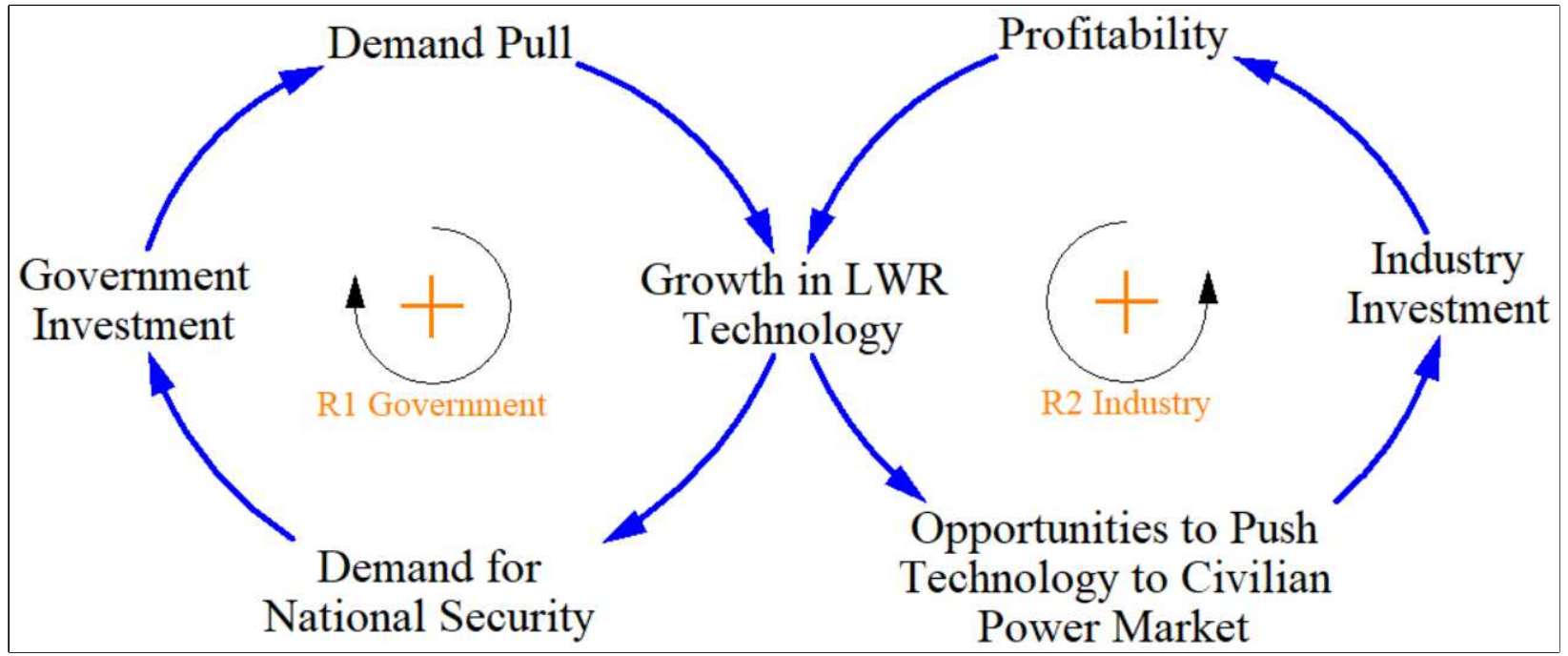

Figure 1 Causal Loop Diagram of Growth in LWR Technology

The profit motive is a powerful objective for decision making within a firm (Gwartney et al. 2018). On the industry side of the CLD, profit opportunity was a motivator for private sector firms to engage in producing LWR technology for military applications. On seeing the success of the technology applied, government continued to generate demand-pull for additional growth in LWR. At the same time, those firms producing the military applications of LWR acquired knowledge on how to build it and how to use it. This stock of knowledge created a profit opportunity for firms to apply LWR technology in the civilian power market while minimizing risks that could arise from uncertainty about an otherwise new technology. For the firms who were part of the military applications of LWR technology, LWR was not new. On seeing profit opportunity, due in part to rising demand for energy, rising input costs of using coal and oil for civilian power, and responding to government interest for civilian nuclear power, industry invested in the technology. Firms with acquired knowledge of LWR technology saw a profitable opportunity to 'push technology' into the civilian power market. During The Turnkey Era, discussed in the next section, early entrant firms lost money on initial investments. But overall, captured market share and additional orders that led to long-term profitability.

These two forces, demand-pull and technology-push, as well as investment from government and industry were key to growth in LWR technology. The leading motivators for each side of the CLD was the demand for national security, on the part of government, and profitability on the part of industry. To be sure, many more factors played into growth in LWR technology. These will be discussed throughout the report. But at a very high level, this CLD illustrates the driving forces (national security and profitability), 
key actions (government and industry investment), and the impact technology (first demand-pull then technology-push). These reinforcing loops illustrate how LWR grew during the period of commercialization. But what the CLD does not illustrate are the balancing loops that act as constraints on the system; they emerged as constraints in the 1970's. For example, after the period of commercialization public opinion and its impact on regulatory oversight of nuclear construction impacted growth. Public opinion and its impact on the waxing and waning of Congressional support for nuclear in civilian applications impacted growth. These balancing forces are, however, largely realities of the postcommercialization timeframe and is beyond the boundary of the analysis of this study on growth to commercialization.

\subsection{Methodology}

The method of this report is two parts investigative and one part analytical, couched in the methods of an integrative literature review (Torraco 2005). The first piece of the investigative part focused on careful review of the literature describing the growth in LWR technology. (Section 2.) The second piece of the investigative part of the study focused on a review of the literature to summarize barriers facing the nuclear industry today. (Section 3.) The investigative portion of the effort set up the analytical part of the study (Section 4). Comparing the lessons of history to barriers today required scrutiny of conditions during the growth in LWR technology versus conditions today. In some cases, historical events and lessons are directly applicable to today; in other cases, while events remain informative, conditions between "then and now" are sufficiently different such that some events did not generate directly applicable lessons.

Figure 2 shows a timeline of LWR commercialization. ${ }^{2}$ It begins in the post-World War II era with the dawn of the US Nuclear Navy led by Admiral Rickover and runs through 1970 at which point the first reactors, Oyster Creek and Ginna, were funded with $100 \%$ private sector capital investment. The timeline can be divided into three main eras: The Nuclear Navy, The Demonstrations Era, and The Turnkey Era. The study reports on the underlying details of this timeline in Section 2.

\subsubsection{Integrative Literature Review}

An integrative literature review is a sophisticated form of research that generates new knowledge on an existing topic (Torraco 2005). This study is conducive to an approach founded in an integrative literature review because it describes the history of LWR technology then draws from the history lessons applicable to today's nuclear industry. The study creates a conceptual framework to use today based on lessons of the past. The systematic approach of this study, two parts investigative to one part analytical, combined with new perspectives on history, fits with the approach of the integrative review.

2 The timeline in Figure 2 addresses the evolution of the commercial LWR industry in the US. Concurrently there were significant efforts to develop commercial nuclear power in other countries, for example in the United Kingdom (UK), in France and, after 1970, brief forays into fast reactors in Russia, the $\mathrm{BN}-600$ and $\mathrm{BN}-800$. The UK developed indigenous Magnox reactors (natural uranium/graphite/CO2) initially for both power and plutonium production in the 1950s. These eventually evolved into the Advanced Gas Reactor (AGR) in the 1960s which is the dominant operating nuclear reactor in the U.K. today. There is a single operating PWR (Sizewell-B -1995) in the UK and plans for potential additional PWRs/BWRs to augment/replace the AGRs. The first nuclear reactors in France were indigenous reactors like Magnox, however, beginning in the 1970s France switched exclusively to PWRs, initially based on a Westinghouse design. Commercial reactor development in Russia began in the 1970s with RBMKs (graphite-moderated/water-cooled) and the Russian version of PWRs (VVERs) which are now dominant. 


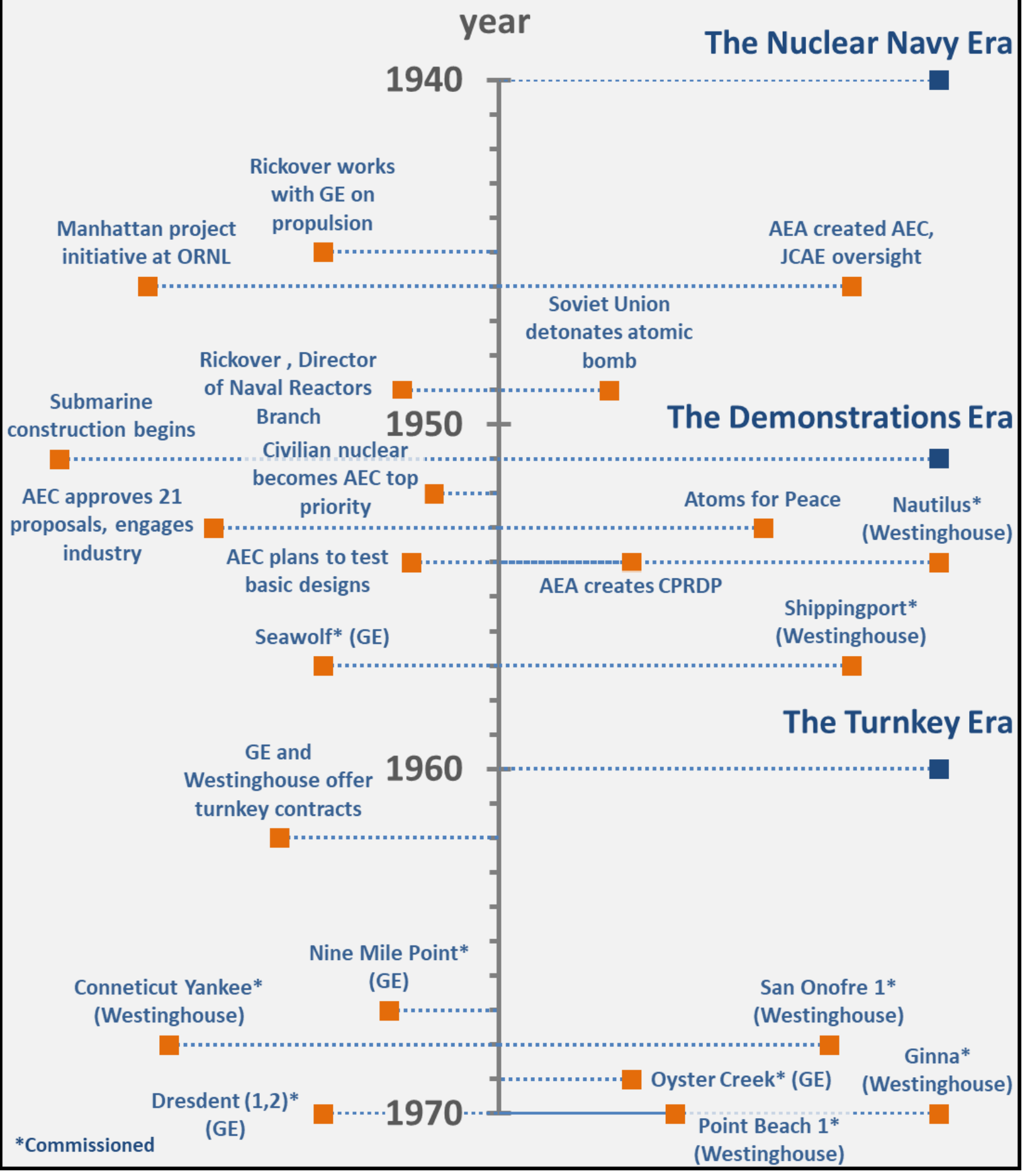

Figure 2 LWR Timeline to Commercialization

\subsubsection{Data Sources}

Researchers found the data underlying the findings of this report in the following way. Analysts leveraged 
document repositories using key search words. The result was over 100 articles that provided context and background for the study at hand. Not all the 100 documents are referenced in the report due to how the researchers applied documents to the analytical framework of the report. However, a comprehensive list of documents reviewed for this study are included in the Appendix.

\subsubsection{Document Repositories}

Analysts made use of conventional document repositories to find documents relevant to the study. This list identifies data repositories used: Google Scholar, national laboratory library data sources, Office of Science and Technical Information (OSTI), and university library data sources.

\subsubsection{Search Terms}

Analysts used key phrases to search the online document repositories. Here is a list, not comprehensive, of search terms used in document searches. Such terms include those such as: nuclear technology innovation; barriers; technology innovation; nuclear; history of nuclear; industry; learning; LWR; learning-by-doing; technology lock-in; path dependency; light water reactor.

\subsubsection{Document Types}

Analysts retrieved many documents to review for usefulness in this study. This list indicates the categories of documents. The number in parentheses shows how many documents of the listed type were reviewed. The appendix of this report contains a bibliography of all sources, it includes those sources cited in the text and listed in references as well as those sources consulted but not referenced: books and book chapters (13); conference papers (1); government reports (14); journals (71); national laboratory reports (9); and think-tank reports (17).

The books and book chapters were largely published by varying university presses and many of these studies were authored by university professors. One source came from a Gen IV International Forum conference. Government reports included sources such as the US Government Accounting Office, the Energy Information Administration, and the US Atomic Energy Commission. Documents from journals were primarily from journals devoted to nuclear energy, economics, or general energy topics. National laboratory reports from previous projects were leveraged where possible. 'Think-tank' reports include those from institutions such as RAND (Research ANd Development) and EPRI (the Electric Power Research Institute). Researchers utilized the data in these sources according to the lens of their experience and expertise.

\subsubsection{Criteria to retain document}

General criteria to retain a document include the extent to which sources addressed nuclear industry barriers, and the documentation and insights provided for empirical detail of historical events in LWR history. 


\section{Growth in LWR Technology: Development, Deployment and Diffusion}

The story of LWR commercialization in the US (i.e. the events listed on the timeline in Figure 2), is one characterized by two external, driving forces and three reinforcing, positive feedback loops. Noted with the earlier CLD, balancing loops (i.e. the constraints on LWR growth) are not discussed in the report. This is because factors that slowed growth in LWR technology, - e.g. negative public perception and costly regulatory scrutiny - largely occurred after the period of commercialization. Although the constraints on growth are critical components of the LWR story, they occur after the period which is the focus of this study.

Figure 3 shows how the links between variables contributing to growth and two variables of interest, listed in blue, that mark growth in LWR technology. 'Construction of LWR civilian reactors' and 'LWR applied on Navy submarines' are the two variables that can be thought of as marking the tangible progress of growth in LWR technology shown in in Figure 1. In this section the text outlines how the events unfolded in four sub-sections. The story of the nuclear navy describes how policymakers and citizens in the US felt the need for greater national security. This drove government investment into developing nuclear technology. The government, essentially, exerted demand-pull on technology development. But at the same time, US manufacturers GE and Westinghouse, government partners in LWR technology development, accrued a significant stock of knowledge on LWR technology, acquired from 'learning-bydoing.' This was valuable knowledge, that when paired with a growing demand for electricity in the US, led to a profit opportunity from pushing LWR technology into the civilian power market. The growing expertise in nuclear technology spawned a recognition of US international nuclear leadership and expertise. President Eisenhower's famous speech "Atoms for Peace" led to international engagement that positioned the US as a global leader in the nuclear industry. The International Atomic Energy Agency resulted from this speech as well as international agreements which led to nuclear development for civilian power in Europe. ${ }^{3}$ As orders for nuclear technology began to originate in European countries, the reputation as an international leader in nuclear started to grow for the US; this was an especially poignant response to the activities of the Soviet Union in the late 1940s. Hence, the narrative includes the international role of the US in LWR development. Discussion of these and other key events in the LWR history is contained in the remainder of this section.

Like an earlier point made in this report, the focus of this study is on the timeframe of LWR commercialization, which runs approximately 1945 to 1970 . Beginning in early 1970s forces began to exert constraints on LWR growth. Although these balancing loops, the portions of the CLD that illustrate system constraints, are not show in Figure 3 because they occurred after the period of analysis, noting that they existed is an important part of the LWR story. These balancing loops can be thought of as that of as constraints arising from both public opinion and supply chain issues. The waxing and waning of public opinion constrained LWR growth by way of its impact on regulatory stringency and Congressional activities in response to it. In the supply chain, because of the rapid rate of orders during The Turnkey Era, began to experience "bottle necks," that is, points where manufacturing capacity could not keep pace with the demand for inputs. These and other current day hurdles, find discussion in Section 3.

\footnotetext{
${ }^{3}$ See IAEA's description for further discussion here: https://www.iaea.org/about/about-iaea.
} 


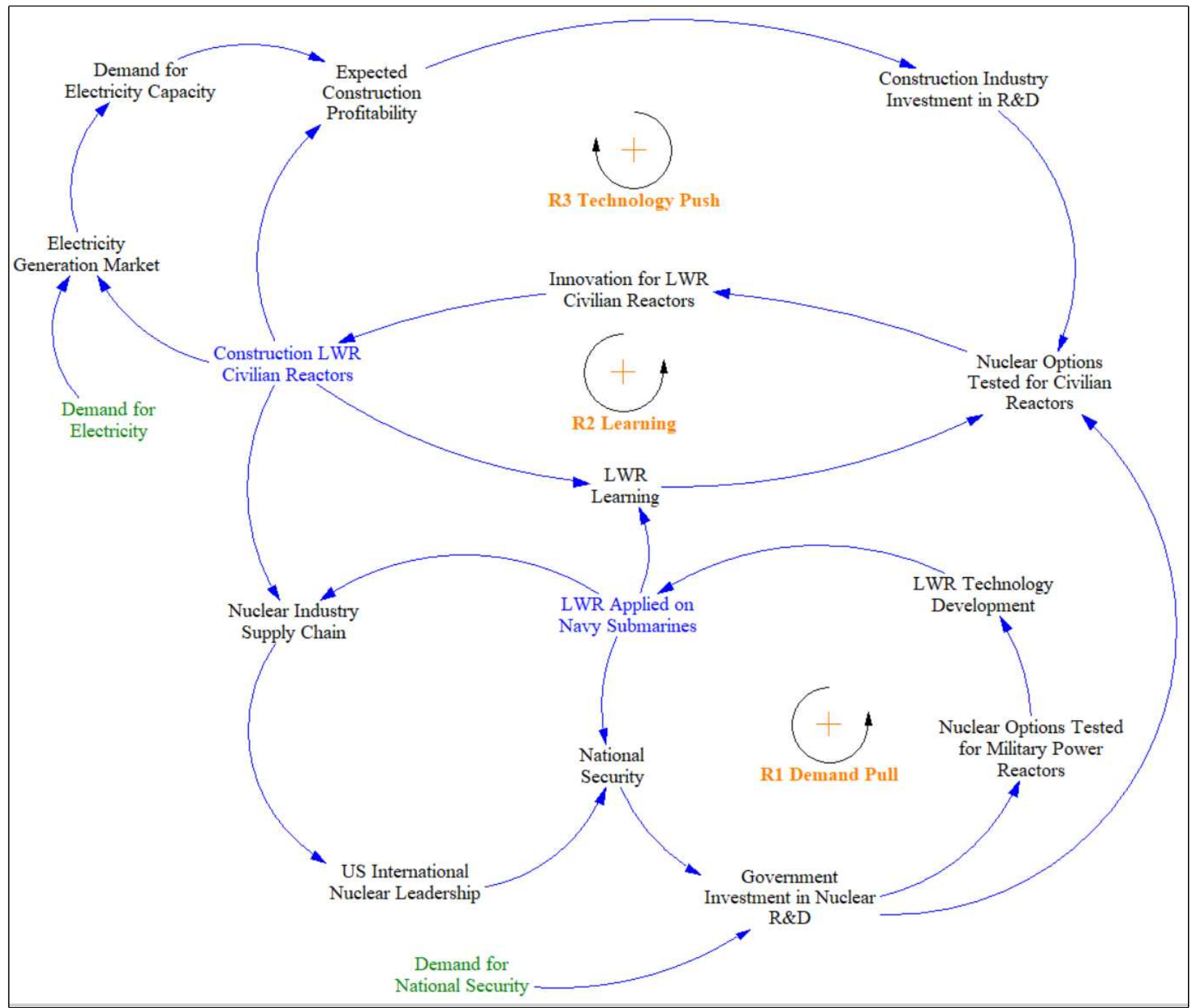

Figure 3 Expanded Causal Loop Diagram of Growth in LWR Technology

\subsection{The Nuclear Navy Era}

In the aftermath of World War II, the United Stated emerged as the world's sole nuclear power. After successfully developing the nuclear bombs that were detonated on Hiroshima and Nagasaki, the Manhattan Project sought to further refine nuclear technologies, and develop secondary applications such as electricity generation and medical isotopes production. In 1946, an activity to develop a nuclear electric generation plant was initiated within the Manhattan Project at Oak Ridge, Tennessee. The bombings at Hiroshima and Nagasaki, however, had made the world aware of the destruction potential of this new technology, and initiated public debate, both at the national level and internationally, over the management of the peacetime development of nuclear science and technology. In the U.S., this resulted in the creation of the Atomic Energy Commission (AEC), which was established by the Atomic Energy Act of 1946. The AEC took over the functions and assets of the Manhattan Project, crystalizing civilian control of nuclear development, and establishing the National Laboratories to carry out crucial research for the nation. The Joint Committee on Atomic Energy (JCAE) had oversight of the AEC. The JCAE was a congressional committee that was tasked with exclusive jurisdiction over "all bills, resolutions, and other matters" related to civilian and military aspects of nuclear power from 1946 through 1977. 
In parallel, the U.S. Navy had recognized the benefits of nuclear energy for propulsion and initiated its own research program. In 1945, Captain (later Admiral) Hyman Rickover, an electrical engineer, was assigned to Schenectady, New York, to work with GE to create a nuclear propulsion plant for destroyers. In 1946, Rickover spent several months at Oak Ridge, where he gradually became convinced that the US Navy should shift its focus from nuclear destroyers to submarines. Although Rickover's views were initially not shared by his immediate superiors, he eventually was named head of the new Nuclear Power Division in the Bureau of Ships, and convinced that LWR technologies were the most viable for nuclear submarines, started work on the design of the pressurized water reactor (PWR) for submarine propulsion, in collaboration with Alvin Weinberg, the Oak Ridge director of research. The design of the PWR later continued at Argonne National Laboratory (ANL) in Argonne, Illinois.

In 1949, Rickover was named Director of the Naval Reactors Branch of the AEC. As chief of the Nuclear Power Division in the Bureau of Ships and Director of the Naval Reactors Branch, Rickover was instrumental in the authorization of the construction of a nuclear-powered submarine in 1951. A landbased prototype, the Submarine Thermal Reactor Mark I (STR Mark I, later re-designated S1W), was built in Idaho at the National Reactor Testing Station, based on a design by ANL and Westinghouse. The STR Mark I was built inside of a submarine hull to better inform on how the marine-based reactor would have to be constructed. Later, it was used to support plant testing and training of operators who were graduates of the US Naval Nuclear Power School. The USS Nautilus was commissioned in 1954, powered by the Submarine Thermal Reactor Mark II (STR Mark II, later S2W), and began operation in 1955.

Meanwhile, GE developed the Submarine Intermediate Reactor (SIR) or Liquid Metal Fast Reactor (LMFR), later designated S1G (land-based prototype) and S2G (marine-based reactor). It was a liquid sodium-cooled, epithermal reactor, a much more technologically advanced system than the $\mathrm{S} 1 \mathrm{~W}$ and S2W that was, more compact, quieter, and thermally efficient, because the higher temperature of liquid sodium (compared to pressurized water) that enabled the production of more superheated steam in the steam generators. The USS Seawolf was commissioned in 1957, but problems quickly arose with the superheaters, which had to be by-passed, resulting in a loss of performance, as well as concerns over the use of sodium in a water environment. Due to these technical difficulties, and the perceived limitations of sodium-cooled systems, GE lost ground to Westinghouse on nuclear propulsion technology, and the reactor powering the USS Seawolf was converted to an S2Wa, a spare STR Mark II reactor, utilizing saturated, rather than superheated, steam. GE sodium-cooled models subsequently were not used for submarines but generated significant experience on LMFR for civilian use.

\subsection{The Demonstrations Era}

Initially, the AEC operated under great secrecy, which meant that all technical information and research results it generated were in its control, all production facilities and nuclear reactors it developed were government-owned, and industry participation was minimal. But in 1949, the Soviet Union detonated its first atomic bomb, crushing the dream of an American monopoly of the nuclear weapon, and igniting the fear that if the world saw the Soviets winning the race for nuclear energy, non-US aligned nations would align with the Soviets. In 1952, the AEC moved civilian nuclear power from last to first priority, due in large part to the fear of losing the nuclear race to the Soviets, but also because of the strong growth of demand for electricity. The Industrial Participation Program (IPP) was established in 1951 to strengthen the AEC's ties with the private sector, to bolster civilian nuclear development. Between 1952 and 1954, the AEC approved proposals from 21 study teams, consisting of more than sixty companies, including utilities, vendors and architect-engineer firms (Krahn 2017). Several IPP participants later became key players in the development of the nuclear industry.

In 1954, the AEC announced plans to test the basic designs at that time under study by building five demonstration reactors within five years (Buck 1983). One of them was the construction of a small 
demonstration reactor at Shippingport, Pennsylvania, to be integrated into the utility grid. The Shippingport project was authorized and appropriated for under the AEA of 1946. The PWR design used for the Nautilus was chosen, since it was known to produce power safely and quickly (albeit not economically, which caused other stakeholders at the time to favor less expensive alternatives). For expediency, a reactor intended for a nuclear-powered aircraft carrier project, that President Eisenhower had just vetoed, was re-purposed for the Shippingport reactor, and Rickover took over its management. The Shippingport Atomic Power Station was completed on schedule in 1957. Duquesne Light Company financed the balance of plant construction, operated, and maintained the entire plant, and reimbursed the AEC for steam produced. The Shippingport reactor used three different cores throughout its lifetime. The first and second cores consisted of a seed-and-blanket design with 93\% enriched HEU (highly enriched uranium) as seed, surrounded by a blanket of natural uranium. For the third core, the same seed-andblanket concept was used, with a U-233 seed and thorium blanket, in a breeder configuration (the Lightwater Breeder Reactor 'LWBR'), with breeding ratio just slightly greater than 1 . The Shippingport project demonstrated not only the technical viability of PWRs for electricity generation, but also that of a publicprivate partnership with a private utility as the owner-operator.

Shortly after the approval of the Shippingport project in 1954, the new policy outlined internationally by President Eisenhower in "Atoms for Peace" resulted in an overhaul of the Atomic Energy Act, and subsequent launch of the Cooperative Power Reactor Demonstration Program (CPRDP). The CPRDP aimed at incentivizing industry participation in the development and implementation of a range of nuclear power reactor concepts. The 1954 Atomic Energy Act (AEA) opened the door to private ownership of nuclear facilities (in contrast to the earlier public-private approach), using fissionable material leased from the Government.

The "three plus one" rounds of the CPRDP provided varying degrees of government support to the private sector for the construction of demonstration nuclear power plants ranging in size from 10 to 400 MWe. It funded LWRs, sodium-cooled reactors, high temperature gas reactors and homogeneous reactors, including molten salt. The role of the private industry was further incentivized by the PriceAnderson amendments to the AEA in 1957. The Price-Anderson Act (Holl, Anders, and Buck 1986) required nuclear power operator to carry the maximum insurance offered privately and established a limited federally-backed accident liability indemnification program. Under the CPRDP, ten small demonstration reactors (5 LWRs, including the Elk River Boiling Water Reactor, and 5 non-LWRs: the Experimental Boiling Water Reactor, built at ANL; the Sodium Reactor Experiment, built in California by North American Aviation; the Experimental Breeder Reactor II, built at Argonne National LaboratoryIdaho, now known as Idaho National Laboratory; and the Homogeneous Reactor Test built at the Oak Ridge National Laboratory), one large demonstration reactor (Yankee Rowe, 134 MWe Westinghouse PWR, 1960), and two commercial-scale ( 400 MWe) PWRs (Connecticut Yankee, 1968 and San Onofre, 1968 ) were built and operated. Figure 4 shows a timeline of completion of the CPRDP projects, as well as others taking place roughly in the CPRDP era. Of the five reactors types initially considered in the program, the Shippingport and EBWR reactors encountered fewer technical problems, but each generated significant experience and contributed to the development of the technology needed to eventually build commercial nuclear power plants using LWR technology in PWRs and BWRs. 


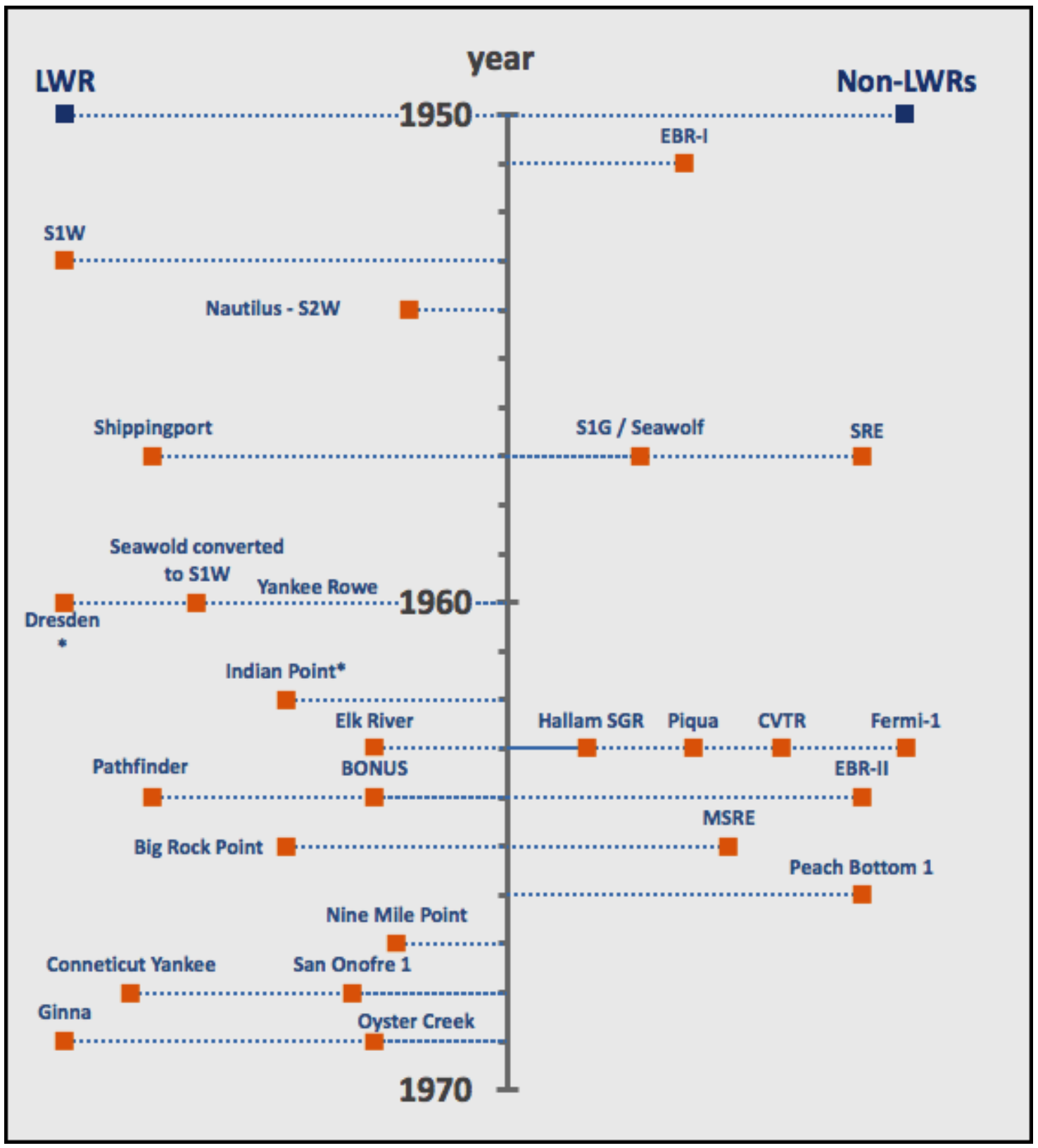

Figure 4 LWR vs non-LWR Timeline

The 1950s saw priorities for the AEC rapidly changing to keep the US ahead in the nuclear race; the potential for learning about new technologies was at times a secondary consideration in exchange for reliability, even though economic sustainability had not yet been proven. In 1953, under the "Atoms for Peace" doctrine, the U.S. showed willingness to guarantee supplies of enriched uranium and provide reactor technology to friendly nations, to encourage the adoption of American technology. The experience accumulated through the US Nuclear Navy program generated momentum for LWRs to leave other technologies behind. Through extensive learning-by-doing ( visually obvious in the higher density on the left of Figure 4,) the export of LWR technology to other countries consolidated its competitive advantage. The decade saw an increasing dominance of LWRs over other technologies (e.g., breeders, gas-cooled) although heavy water reactors continued to be favored in Canada, and indigenous gas-cooled options 
were pursed in the UK (with a single LWR in 1995) and to some degree in France (exclusively PWRs from 1970 on).

\subsection{The Turnkey Era}

During the period of their involvement with government partners, both in military applications and demonstration programs, contract manufacturers GE and Westinghouse built a wealth of knowledge regarding how to construct LWR reactors. The learning that accrued during this engagement provided these manufacturers an important market opportunity to leverage to nuclear reactor construction for civilian power and initiate a phase of privately financed, demonstration programs. This notion is motivated by the large financial losses these firms incurred during the phase known as "The Turnkey Era," in return for capturing significant market share in nuclear construction (Burness, Montgomery, and Quirk 1980b). It is during this period that LWR technology reached the culmination of technology maturation and commercialization; the nuclear power plants at Ginna and Oyster Creek were exclusively funded by the private sector (Krahn 2017). Similarly, Dresden Unit 1 was funded without government support but because it is a smaller scale an Oyster Creek, both BWRs, Oyster Creek marks the first fully commercialized BWR (Krahn 2017).

Understanding all the relevant factors in corporate level decision-making, from a perspective external to the firm, is difficult; data used in corporate decision making is proprietary and thus unavailable to include in this report. However, factors that would have likely been relevant to GE and Westinghouse can be inferred to understand their decision to proactively engage in the nuclear construction industry. Noted earlier, these firms captured knowledge and experience that could be applied in the civilian power market from their support to the US Navy's nuclear power program. One can imagine that the decision makers at GE and Westinghouse must have been wondering if investing in nuclear generating capacity for the civilian power market would be worth it. Questions corporate analysts may have considered could have included that of expected profitability and market share. The next few paragraphs discuss aspects of the economic environment during that time, which would have been relevant factors in investment decisionmaking.

The economic environment at the end of the 1950's and early 1960's was one of optimism. The US was in an economic expansionary phase, brought on by the end of World War II and the Korean War. Gross Domestic Product (GDP) grew annually at a rate of nearly $3.5 \%$ at the end of the 1950's, rising to just over 5\% per year by the early 1960's (BEA n.d.). Economic growth required electric power, so correspondingly, demand for electricity grew. Figure 5 (a) shows annual growth in retail electricity sales, beginning in 1960 and spanning to 1980 . At the beginning of the 60's, forecasted growth shown as the blue box in panel (a) of the Figure 5 portrayed an optimistic outlook for the electricity market. The blue box shows the data used to generate the forecast. A forecast for demand in generation capacity, an input into the electricity market, correspondingly would have looked similar. Contrast this to the actual demand beginning in the 1970's that reflects the disruptions in the energy markets during the energy and oil crisis.

In addition to optimistic demand projections, other motivators impacted the drive for deploying nuclear technology to civilian power markets (Burness, Montgomery, and Quirk 1980a). Demonstration programs of the previous decade revealed that LWR technology was feasible on technical and economic merits. In the coal industry, increasing capital and fuel costs contributed to the rising cost of coal-generated electric power, input costs rose about $15 \%$ at the beginning of the 1960's. This rise in cost was due to rising costs to mine coal, and due to growing public concern for environmental issues generally, stack emissions specifically. By the end of the 1960's coal mining safety legislation reflected public sentiment over this issue. These rising costs coupled with a view of nuclear power as a clean generating source led to nuclear as an attractive alternative for baseload generation, especially in the Northeastern US where coal was a primary feedstock. By the early 1970's, there were projections that forecast a need for 1000 large power reactors in the US by the year 2000 (US AEC 1974). 
Figure 5 (b) shows the distribution of electric power suppliers from 1960 to 1980 . The orange area illustrates the increasing fraction of electricity generation from nuclear reactors. Coal production steadily reduced creating a capacity opportunity that nuclear generators filled.

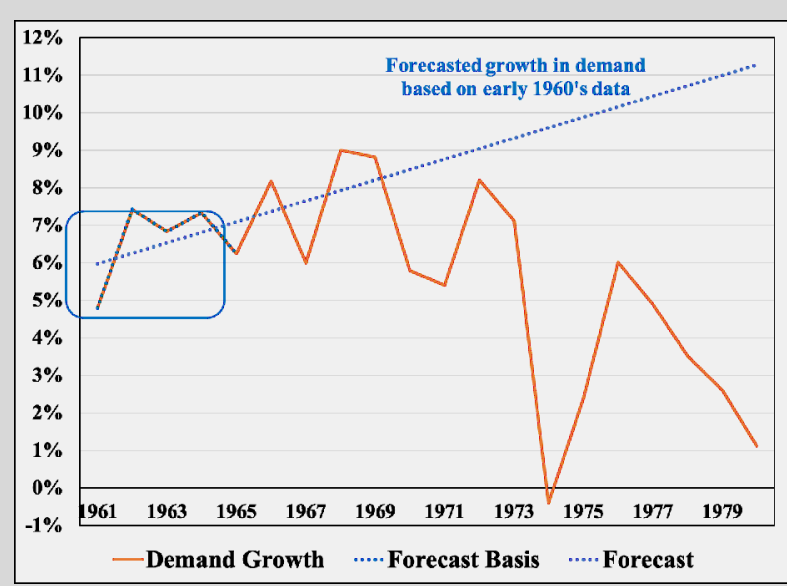

(a) Electricity Demand

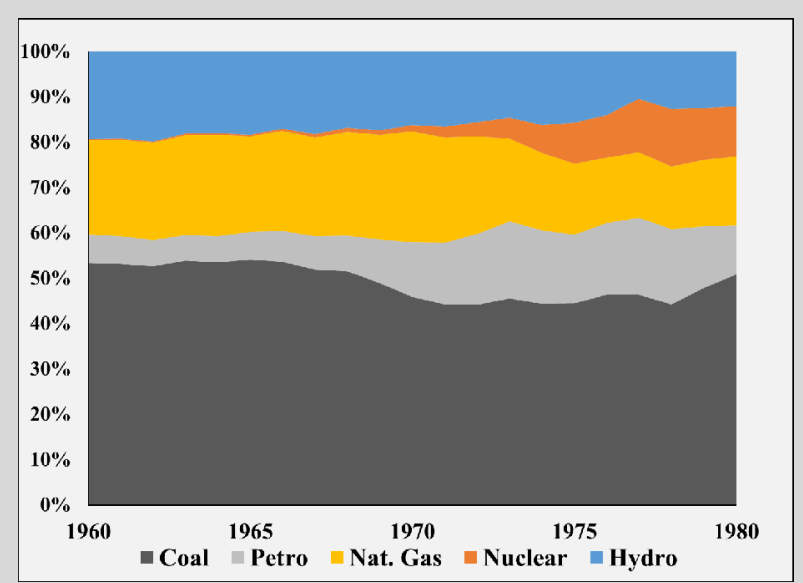

(b) Supply Technologies

Source: author calculations on Energy Information Administration electricity sales and generation data (EIA 2020b).

\section{Figure 5 Electricity Market Conditions 1960 - 1980}

Despite the boom in economic growth at the end of the 1950's and early 1960's, investment in new nuclear reactors had reached a halt. Table 1 shows orders for nuclear reactors of all types. In the early 1950s there was a flurry of activity in the nuclear industry, where many orders were placed. But then the enthusiasm waned, such that by 1959, the order for the Big Rock Point plant was the last one placed for three years. Burness, Montgomery, and Quirk (1980b) state that "the AEC was dragging their feet." The AEC reduced extensive subsidy programs for new commercial reactors. Yielding to pressure from utilities and nuclear manufactures, Congress appropriated \$20 million in 1961 (\$134 million in 2019 USD) for subsidies to nuclear construction. New construction at Connecticut Yankee (i.e., the Haddam Neck plant) and San Onofre 1 were beneficiaries of this new program and AEC financing. 
Table 1 Reactor Orders in the 1950's

\begin{tabular}{|c|c|c|c|c|}
\hline Plant & Order Date & NSSS/AE & $\begin{array}{c}\text { Net Capacity } \\
\text { (MWe) }\end{array}$ & Type \\
\hline Shippingport & Jul-53 & WEST/S\&W & 60 & PWR \\
\hline Indian Point Station 1 & Feb-55 & $\mathrm{B} \& \mathrm{~W} / \mathrm{VIT}$ & 265 & PWR \\
\hline Dresden Station 1 & Jul-55 & GE/BECH & 200 & BWR \\
\hline Yankee Station 1 & Jun-56 & WEST/S\&W & 175 & PWR \\
\hline Enrico Fermi Unit 1 & Mar-57 & $\mathrm{PRDC} / \mathrm{G} / \mathrm{CA}$ & 60.9 & FBR \\
\hline Pathfinder Atomic & May-57 & $\mathrm{AC} / \mathrm{PSE}$ & 58.5 & BWR \\
\hline Hallam & Sept-57 & $\mathrm{AI} / \mathrm{BECH}$ & 75 & SGR \\
\hline Humboldt Bay & Feb-58 & GE/BECH & 65 & BWR \\
\hline Elk River Plant & Jun-58 & $\mathrm{AC} / \mathrm{S} \& \mathrm{~L}$ & 22 & BWR \\
\hline Peach Bottom Station & Nov-58 & GAC/BECH & 40 & HTGR \\
\hline $\begin{array}{r}\text { Carolinas-Virginia } \\
\text { Tube Reactor }\end{array}$ & Jan-59 & WEST/S\&W & 17 & HWR \\
\hline Piqua Nuclear Power & Jun-59 & $\mathrm{AI} / \mathrm{H} \& \mathrm{~N}$ & 11.4 & OCR \\
\hline Big Rock Point & Dec-59 & GE/BECH & 72 & BWR \\
\hline \multicolumn{5}{|l|}{ Notes: } \\
\hline \multicolumn{2}{|l|}{ AC: Allis-Chalmers } & \multicolumn{3}{|c|}{ HWR: Heavy water reactor } \\
\hline \multicolumn{2}{|l|}{ AE: Architect-Engineer } & \multicolumn{3}{|c|}{ NSSS: Nuclear Steam System Supplier } \\
\hline \multicolumn{2}{|l|}{ AI: Atomics International } & \multicolumn{3}{|c|}{ OCR: Organic cooled reactor } \\
\hline \multicolumn{2}{|l|}{ B\&W: Babcock and Wilcox } & \multicolumn{3}{|c|}{ PSE: Pioneer Service \& Engineering } \\
\hline \multicolumn{2}{|l|}{ BECH: Bechtel } & \multicolumn{3}{|c|}{ PRDC: Power Reactor Development Co } \\
\hline \multicolumn{2}{|c|}{ GAC: General Atomic Corporation } & \multicolumn{3}{|c|}{ SGR: Sodium gas reactor } \\
\hline \multicolumn{2}{|l|}{ GE: General Electric } & \multicolumn{3}{|c|}{ S\&L: Sargent and Lundy } \\
\hline \multicolumn{2}{|c|}{ G/CA: Gilbert/Commonwealth Assoc. } & \multicolumn{3}{|c|}{ S\&W: Stone and Webster } \\
\hline \multicolumn{2}{|l|}{ H\&N: Holmes and Narver } & \multicolumn{3}{|c|}{ WEST: Westinghouse } \\
\hline \multicolumn{2}{|c|}{ HTGR: High-temperature gas reactor } & \multicolumn{3}{|l|}{ VIT: Vitro } \\
\hline
\end{tabular}

Source: (DOE-NE 1980)

Due in part to the successful start of construction at Connecticut Yankee and San Onofre, and because of the extensive learning they had accrued during the phase of military applications and demonstrations, GE 
and Westinghouse were keen to generate demand for new orders of nuclear reactors. GE initiated, then Westinghouse followed, a unique contract type to incentivize utilities to purchase new reactors, turnkey contracts. Westinghouse had the contract for Connecticut Yankee's Haddam Neck plant and the plant at San Onofre. Based on early negotiations with Jersey Electric, GE announced in 1963 it would build the plant at Oyster Creek under terms of a turnkey contract. It was this contract that set off The Turnkey Era (Burness, Montgomery, and Quirk 1980b). Historically turnkey contracts were not offered in the utility business because of the large risks placed on the manufactures. But GE and Westinghouse offered such contracts, helping to break the construction gridlock.

A turnkey contract is, as the name suggests, one wherein the contractor 'hands over' to the utility the keys to the reactor. These include firm-fixed price contracts, which means that before construction on the reactor begins, the utility and the contractor agree to a price for delivery of the finished product. In this case, the manufacturing contractor assumes the responsibility (and the risk) for design, construction, testing, and building according to regulatory standards. The price is negotiated to cover all possible contingencies, if costs turn out to exceed those that were planned it is the contractor who bears this risk. Alternatively, if costs turn out to be less than what was planned, the contractor captures the difference as profit. The price that contractors offered to utilities was based on the next best alternative supply technology. GE and Westinghouse offered prices that were competitive with utilities maximum willingness to pay for fossil fuel produced electricity.

GE and Westinghouse offered 13 of these contracts during the period of 1962 to 1966, at the same time seven reactors were built under conventional (cost plus) contracting terms. Table 2 lists these 13 reactors built under turnkey terms.

Table 2 Reactor builds on Turnkey Terms

\begin{tabular}{|c|c|c|c|c|c|c|c|}
\hline Unit & $\mathbf{A} \& \mathbf{E}$ & $\begin{array}{l}\text { Vendor- } \\
\text { NSSS }\end{array}$ & $\begin{array}{c}\text { Order } \\
\text { Date }\end{array}$ & MWe & $\begin{array}{l}\text { Reported } \\
\text { Cost to } \\
\text { Utility }\end{array}$ & $\begin{array}{l}\text { Estimated } \\
\text { Cost to } \\
\text { Vendor }\end{array}$ & $\begin{array}{c}\text { Estimated } \\
\text { Loss }\end{array}$ \\
\hline Haddam Neck & S\&W & WEST & Dec-62 & 575 & 428 & 614 & 185 \\
\hline San Onofre 1 & $\mathrm{BECH}$ & WEST & Jan-63 & 450 & 437 & 540 & 103 \\
\hline Dresden 2,3 & S\&L & GE & Feb-65 & 1618 & 808 & 1702 & 894 \\
\hline Ginna & GIL & WEST & Aug-65 & 490 & 342 & 663 & 321 \\
\hline Millstone & EBAS & GE & Sep-65 & 690 & 400 & 750 & 350 \\
\hline Oyster Creek & $\mathrm{B} \& \mathrm{R}$ & GE & Dec-63 & 650 & 371 & 700 & 330 \\
\hline Robinson 2 & EBAS & WEST & Jan-66 & 700 & 321 & 738 & 416 \\
\hline Point Beach 1, 2 & $\mathrm{BECH}$ & WEST & Feb-66 & 994 & 597 & 1356 & 758 \\
\hline Monticello & $\mathrm{BECH}$ & GE & Apr-66 & 545 & 433 & 693 & 260 \\
\hline Quad Cities 1, 2 & S\&L & GE & Apr-66 & 1618 & 824 & 1846 & 1022 \\
\hline \multicolumn{8}{|c|}{$\begin{array}{l}\text { Notes: } \\
\text { 1/ Monetary units in millions of } 2019 \text { USD } \\
\text { 2/ EBAS: Ebasco } \\
\text { GIL: Gilbert Associates }\end{array}$} \\
\hline
\end{tabular}

Source: author calculations on data in (Krahn 2017, Burness, Montgomery, and Quirk 1980b, DOE-NE 1980)

Observations of cost overruns, unforeseen construction delays and other uncertain events outside of project management control may cause one to question why a vendor would offer to bear this entire set of 
project risks, which was the reality with turnkey contracts. However, from the perspective of the early 1960's this philosophy seems quite logical. By that point, very few utilities had purchased nuclear reactors for civilian power production; in fact, utilities had very little experience in the nuclear construction business, let alone providing project oversight of the architect-engineer. On the other hand, it was GE and Westinghouse who had been heavily involved in developing the technology, and the industry. They were in a much better position to be aware of the risks, including sufficient knowledge regarding how to mitigate such risks. Further, scaling the industry from projects on the order of 50 to 600 MWe required information that few in the industry possessed, except for GE and Westinghouse. Moreover, because of their unique acquisition of knowledge and intellectual property, GE and Westinghouse were in a position to extract quasi-rents (Burness, Montgomery, and Quirk 1980b). Quasirents refer to the profits attained from a paid off investment and creating barriers to entry for new competitors. Burness et al. suggest that the turnkey era in nuclear construction can be considered a demonstration program that GE and Westinghouse invested in so that they could gain additional learning (and market share) for the second generation of LWR technology and second wave of nuclear orders. The financial investment in The Turnkey Era is more understandable in the context of a market potential of hundreds of future orders; in the early 1970s up to 1000 were forecasted by year 2000 (US AEC 1974).

Amongst industry stakeholders at the time, there was debate about the appropriateness of turnkey contracts as a method of moving the nuclear industry forward. The dichotomous view of the role of turnkey contracts is best represented with the summary from Burness et al. They quote the President of Consumer Power who expressed concern that the prices of turnkey contracts cover contingencies that may never occur and that any "reasonably knowledgeable utility" does not need to pay for such assurances. Conversely, the president of Rochester Gas and Electric argued that he would never authorize his utility to build a reactor with a series of small projects, "in bits and pieces." His take was precisely because utilities were not in the business of overseeing nuclear construction, that construction firms were those who should bear associated construction risks. Despite the discrepancy on which view held most merit, what is true is that The Turnkey Era seemed to break the gridlock in nuclear construction that ended the 1950's and started the 1960's. And surprisingly, it also caused a boom in nuclear construction following the offering of turnkey contracts.

The data in Table 2 show that the debate regarding economic viability of turnkey contracts may have been warranted. The cost data listed in "Costs Reported to the Utility" show the turnkey contract price. The purchasing utility could plan on this to be the cost of their new nuclear reactor. The data in the estimate column show what Burness, Montgomery, and Quirk (1980b) show found the vendor cost to be. They computed this data from various, compiled published sources since the vendors did not release this information publicly. Comparing this to utility cost, Burness et al. estimated the losses on each project that GE and Westinghouse incurred. Summing the data in the loss column finds that the estimate of combine losses across projects totals $\$ 4.6$ billion (2019 USD).

With estimated losses of that magnitude, it is puzzling how the turnkey era broke up the gridlock that stalled the industry at the late 1950s and early 1960s. Sizeable losses on the part of GE and Westinghouse may lead one to believe financial losses like these would have ruined the industry. However, the turnkey era, and these early builds in it, led to factors that changed the motivating drivers for continued nuclear industry expansion and LWR growth. Utilities developed a stock of knowledge about nuclear reactors and incentives leading to utility profitability changed.

Breaking the gridlock in nuclear construction so that a few years of construction projects and experience could pass, utilities where at a point of having acquired expertise to provide oversight to contract builders. Information needed about scaling up the industry from demonstration-sized projects on the order of 50 MWe to much larger power plants was now more widely available. Utilities moved into a position could actively participate in the design and construction of nuclear plants and were leveraging expertise needed 
to manage cost-plus contracts. These were all good reasons to return to conventional contracting. But there were some inherent biases that motivated this return as well.

Early theoretical analysis on rate of return regulation exposed the link between the presence of an active regulatory constraint and increasing capital investment (Averch and Johnson 1962). In extensions of the theory set out by Averch and Johnson, others discovered how firms respond to the presence of a regulatory constraint (Burness, Montgomery, and Quirk 1980a, Joskow 1974). The theory describes that when utilities are governed by rate of return regulation there is a motivation to pass increasing costs onto the consumer base. While doing so, firms - including utilities - can increase allowable profits because of established rate of return on invested capital. Burness, Montgomery, and Quirk (1980a) report that this factor contributed to the end of the turnkey era, followed by a boom in orders for nuclear construction under conventional contracting terms. Bluntly put, as long as utility regulators allowed a fixed rate of return on capital investment and pass-through to consumers, higher capital costs directly enhanced eventual utility revenue.

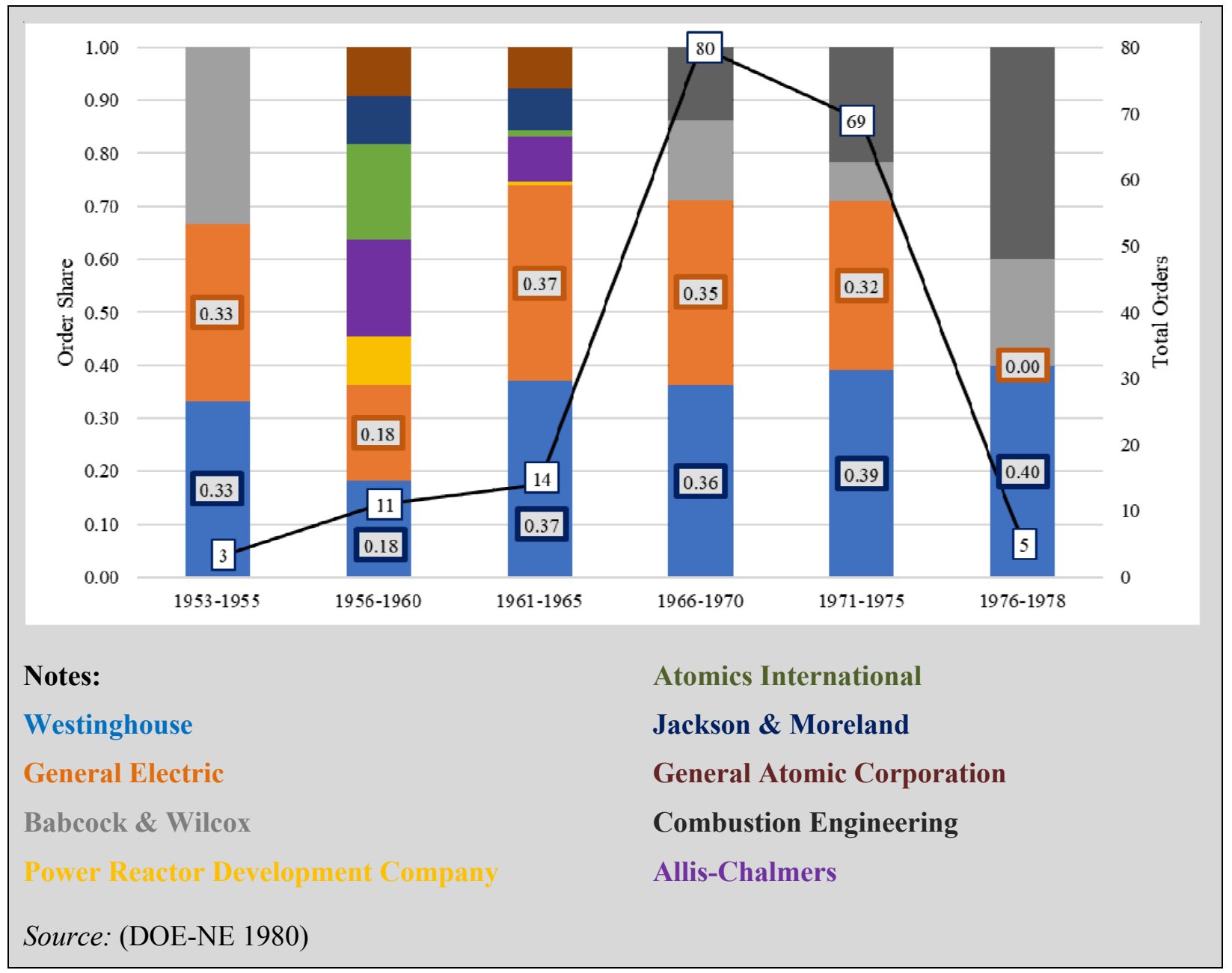

Figure 6 Nuclear Orders and Market Share

As the nuclear construction industry heated up, bottlenecks in the supply chain started to occur (Burness, Montgomery, and Quirk 1980b). Although the exact reasons are unknown, GE and Westinghouse discontinued their offerings of turnkey contracts. ${ }^{4}$ Perhaps $\$ 4.6$ billion in losses contributed to this, or it 
could have been because the incentives of such contracts were no longer needed to generate orders for new construction. The second half of 1966 saw 13 new orders under conventional contracting terms of cost-plus. Then 31 orders in 1967, 16 in 1968 and 8 in 1969 closed out the decade. Figure 6 shows how this boom continued through 1978 where nuclear capacity in the US doubled every two years. In the period of the boom, the industry grew by $40 \%$ (Burness, Montgomery, and Quirk 1980b). This growth occurred in spite of the fact that under conventional arrangements the cost utilities bore increased by roughly $35 \%$ (Helmuth 1988).

While a deep examination of financial statements from GE and Westinghouse is beyond the scope of this study, and proprietary data, Figure 6 shows how the market share of orders for new nuclear construction evolved over the period. It sheds light on the return on a $\$ 4.6$ billion dollar investment. GE and Westinghouse retained the dominant market share throughout the period, although Babcock \& Wilcox and Combustion Engineering intermittently had periods of a notable share of new orders. So, although profits attained by each firm are not known, the market share is a good indicator. During the turnkey era, losses to GE and Westinghouse accrued over 13 nuclear reactor units. In the period that followed, when conventional, cost-plus contracting returned, the combined total new orders for nuclear construction of these two firms totaled 108 units. However, not all ordered units resulted in built projects.

\subsection{Role of International Engagement}

Nuclear energy, since its inception, has been a technology whose markets and supply chains have had an inherently global character. Initially, only six countries developed their own reactor technologies indigenously. These countries included the US, UK, Sweden, USSR (the Union of Soviet Socialist Republics), France, and Canada. Countries that subsequently went on to develop nuclear energy programs did so based on technologies supplied by the first-generation of technology suppliers. For these countries, the choices concerning the selection of reactor vendor and supplier state also largely led to enduring choices concerning a reactor technology. ${ }^{5}$

Among the six first-generation suppliers of technology listed above, the US alone became a supplier of reactor technology to fourteen countries. These included Belgium, Brazil, China, France, Italy, India, Japan, Mexico, South Korea, Slovenia, Spain, Sweden, Switzerland and Taiwan. ${ }^{6}$ This wave of technology transfer from the US to buyer countries was largely led by three reactor vendor companies Westinghouse, GE and Combustion Engineering. ${ }^{7}$

${ }^{4}$ GE ended turnkey contracts in 1966 and Westinghouse, officially, ended them in 1971. Westinghouse did not take on any new orders under turnkey terms after 1966.

${ }^{5}$ Exceptions include France which initially embarked on development of gas cooled reactors based on its own technology, it switched to light water reactors when it appeared that the economic case for these reactors was more compelling as they were better suited for energy production. (Hecht 2009) Similarly, although India's first nuclear power plants were based on boiling water reactor technology supplied by GE, India's nuclear program later shifted to focus predominantly on heavy water reactors as part of a "three-stage" nuclear strategy to eventually transition to reactors that would utilize domestic reserves of Thorium..

${ }^{6}$ Additionally, and preceding many of these transfers of commercial reactor technology, the US supplied high enriched uranium and research reactors to 41 countries as part of its Atoms for Peace Program. Over time, the high enriched uranium supplied for research purposes came to be seen as a proliferation risk and significant efforts were undertaken to convert the research reactors to use low enriched uranium.

${ }^{7}$ Combustion Engineering's reactor business was acquired by Westinghouse in 2000. Its main overseas contract was with Korea Heavy Industries and Construction for the supply of PWR technology to that 
Of the 442 reactors in operation today, 299 are PWRs and 65 are BWRs (IAEA 2020). The global dominance of these two reactor technologies can largely be attributed to the commercial success of American reactor vendor companies. ${ }^{8}$

\subsubsection{Securing market dominance through technology transfer, localization, and financing}

The success of American reactor vendor companies can be attributed to the attractive terms offered to buyer countries as part of the reactor contracts. Specifically, American reactor vendors proposed phased programs of localization to buyer countries - offering initially to supply reactors on a turnkey basis for the first few reactor units while also playing the role of the architect-engineer for these early projects. For subsequent projects, the American vendors worked with local companies to accelerate the localization efforts. Such an approach was adopted with significant success in France, Japan, the Republic of Korea (South Korea), and most recently in China. It is also worth noting here that, with the exception of France, the buyer countries had little expertise in reactor design, development, construction and operation, which relied to a significant degree on the workforce of the supplier country for these specialized skills, at least initially. Offers of workforce development, which were part of the reactor contracts, were also therefore a significant determinant in the choice of a vendor company and country. In Korea, for example, the first three reactors - Combustion Engineering designs - were all built on a turnkey basis. By the time construction of the fifth reactor started, Korea had created a domestic architect-engineer firm which was a sub-contractor for that project. By the 1980s, in a reversal of roles, Korean companies had become the prime contractors for the nuclear plant construction projects. ${ }^{9}$ Over this trajectory of development of nuclear energy in Korea, on the job training given to Korean personnel by Combustion Engineering staff was essential for the localization of technology and development of the workforce (IAEA 2011, Verma 2012). The development of the Japanese nuclear energy program followed a similar trajectory with Westinghouse transferring PWR technology to Toshiba and General Electric transferring BWR technology to Hitachi.

Although these global transfers of reactor technology and the accompanying transfer of intellectual property, particularly as concerns China, have recently come under criticism, it is important to remember that reactor contracts between supplier and buyer countries have always been contingent on varying degrees of technology transfer and localization since the very outset of the nuclear industry (Metzler 2012). Higher levels of technology transfer and localization have frequently been seen by the vendor countries as a way to improve the attractiveness of the reactor contract for the buyer country. Another factor that enabled American reactor vendor companies to secure market dominance was attractive offers of financing as part of reactor contracts. The financing was carried out through the American ExportImport (EXIM) bank and has historically included support for large reactor vendors as well as smaller supply chain companies. ${ }^{10}$

country.

8 The third most predominant reactor technology is the pressurized heavy water reactor (forty-eight reactors globally), followed by the light water cooled, graphite moderated RBMK designs of Russian origin (13 reactors), Gas cooled and Graphite moderated reactors (14 reactors) and fast breeder reactors (3 reactors).

${ }^{9}$ The approach taken in Korea, which followed a trajectory of starting from imitation to innovation in high technology sectors such as nuclear energy, has been observed in several countries that developed industrial capacity late in the twentieth century (Kim 1997, Amsden 1992)

${ }^{10}$ The EXIM bank has provided financing for reactor projects in Taiwan, South Korea, Mexico, Spain, 


\subsubsection{Diffuse ownership and longevity of reactor companies}

Although Westinghouse and GE are even today regarded as American companies, it is worth noting that the ownership of these companies has shifted over time. The shifting ownership, particularly during business difficulties, of these companies has been the result of important partnerships forged with the companies that had initially purchased reactor technologies from them. For example, Westinghouse's nuclear energy business was purchased by British Nuclear Fuels Ltd (BNFL) in 1998 with subsequent acquisition of BNFL's stake by Toshiba in 2006. ${ }^{11}$ Similarly GE entered into a merger with Hitachi in 2007.

Thus, the transfer of reactor technology to buyer countries, emergence of new vendors in these countries and subsequent partnerships between the original and new vendor companies and countries could be viewed as a mechanism that has enabled a longevity of nuclear reactor companies, their workforces and their technologies.

\subsubsection{Buyer countries as design laboratories}

The buyer countries listed above have not only provided markets for American reactor technologies, but have also, in some cases, influenced the trajectory of reactor design and development in the US. Two notable relatively recent examples of this phenomenon are seen in the development of the ABWR and the AP1000.The ABWR for example, started as a joint design project involving both Hitachi and GE engineers. The ABWR design project was initiated to develop a new BWR for a Japanese market but the design later became part of the American Advanced LWR Program as well as part of the Utility Requirement Document through which reactor designers and utilities sought to jointly define the desirable characteristics of the reactors that were developed in the US in the aftermath of the Three Mile Island Accident (Taylor 1989). ${ }^{12}$ Similarly, the AP1000 reactor also emerged from a design effort initiated in the mid-1980s. ${ }^{13}$ This reactor was initially intended to be a smaller 600 MWe reactor but was scaled up to a larger power capacity to improve its economic competitiveness in the face of falling gas prices. The scaled up variant was in fact based on a larger variant of the AP600, the EP1000, which had been designed in collaboration with European utilities for European markets (Adomaitis, Saiu, and Oyarzabal 1998, King, Saiu, and Kallio 2001). Thus, reactor design projects initiated or further developed outside the US, in initial buyer countries, appear to have shaped the domestic trajectory of reactor technology

Brazil, the Czech Republic, Bulgaria, United Arab Emirates, and Romania. The most recent example of EXIM bank's work in the nuclear energy sector is financing of USD 2 billion dollars provided to the UAE Barakah project. Although the main reactor vendor for this project is not an American company, several American companies are involved in the supply chain for this project. These companies include Westinghouse, CH2M Hill, Bechtel, as well as twenty other smaller supply chain companies WNA (2020)

${ }^{11}$ Toshiba sold its entire stake in Westinghouse to Brookfield Business Partners in 2018, following bankruptcy filings by Westinghouse in 2017.

${ }^{12}$ Emulating the American effort, European utilities too embarked on a similar initiative which was called the European Utility Requirement Document (Roche 2001).

${ }^{13}$ In all, four reactors were developed as part of the ALWR program - two PWRs and two BWRs - with a passively-cooled BWR and PWR each also an actively cooled BWR and PWR each. The two reactor designs with active safety systems were referred to as "evolutionary" reactors as they drew significantly on prior reactor designs and improved them further. Taylor (1989) explained that the smaller power ratings were selected for the passive reactors initially to give the American utilities the option of a smaller reactor and incorporate the new passive safety features in a cost-effective modular design. 
Retrospective analysis of LWR technology: lessons for today

May 15,2020

evolution. 


\section{Roadblocks in the Nuclear Industry}

The purpose of this section is to set a framework for the comparison of historical events described in Section 2. This section summarizes barriers facing the nuclear industry today. It is not an exhaustive list of barriers, nor is it an in-depth treatment of barriers listed, but instead this section is a high-level summary of issues that need to be overcome for advanced nuclear concepts adopted in the civilian power market to grow.

\subsection{Technical, Safety, and Licensing}

\subsubsection{Licensing Hurdles}

The current NRC licensing regime and staff expertise for power reactors is generally LWR-centric. Therefore, LWR-based advanced reactors (e.g., NuScale) have not yet, and are unlikely, to have significant licensing issues. However, there is limited staff expertise in non-LWR technologies, although there is some historical precedent for non-LWR licensing-related activities: FFTF, PRISM and CRBR Sodium Fast Reactors, and MHTGR/NGNP gas-cooled reactors. Licensing of research and test reactors follows a different approach than that for power reactors. As such, the NRC has licensed an acceleratorbased system for the production of medical isotopes (SHINE).

Many/most proposed, non-LWR advanced reactors are generally Small Modular Reactors (SMRs) or micro-reactors and span a broad range of coolants (i.e., liquid-metal, gas, molten salt), configurations (i.e., solid fuel rods, particles, pebbles fluid fuels), and power levels (SMRs $<300 \mathrm{MWe}$; micro-reactors $<20$ MWth). Many/most advanced concepts, particularly SMRs, include "Integral" systems with reduced piping and hence reduced potential for loss-of-coolant accidents (LOCA), low pressure coolants, low source terms, low excess reactivity, walk-away-safe capabilities.

What the NRC will require to support the licensing of new advanced, and especially non-LWR reactors and demonstrate "adequate safety" is unknown (e.g., level of experimental data; need for prototype/demo; length of time for the licensing process; etc.). Challenges include limited staff expertise, and the absence of a licensing approach for systems relying heavily on passive safety vs. engineered safety systems; what needs to be analyzed and the adequacy of existing tools for the safety analysis; source term; staffing for operations and security; etc.

There have been many attempts over the years to develop "technology-neutral" approaches for licensing of non-LWR reactors (Samanta 2019, 2020). Recently, the NRC announced a vision and strategy to ensure that the NRC is ready to review potential applications for non-LWR technologies effectively and efficiently. To achieve the goals and objectives, as stated in the NRC's vision and strategy, the NRC has developed near-term (within 5 years), mid-term (5-10 years), and long-term (beyond 10 years) implementation plans (NRC 2016, 2017a, b).

In addition, there is an ongoing effort to address these challenges via a proposed approach to a rulemaking to develop the regulatory infrastructure to support the licensing of advanced nuclear reactors. This rulemaking would revise the NRC's regulations by adding a risk-informed, technology-inclusive regulatory framework for commercial advanced nuclear reactors in response to the Nuclear Energy Innovation and Modernization Act (NEIMA) (Finan et al. 2016).

\subsubsection{Technical and Safety Issues}

Many of the Technical Barriers faced by advanced reactor concepts being proposed today are similar in principle to those discussed above for licensing.

- Proposed LWR-based systems (e.g., NuScale) share common elements with current commercial PWRs (e.g., fuel and fuel assembly although some minor differences), but employ an "'integral" 


\section{Retrospective analysis of LWR technology: lessons for today}

May 15,2020

xxiii

approach where the reactor and steam generator(s) are contained in a single vessel to eliminate piping that is the main source of Loss-of-Coolant-Accidents (LOCA) in conventional PWRs hence enhanced safety, but these "integral reactors" have never been built and operated...

- Other than the new AP-1000s at Vogtle (and to some degree the final completion of TVA-Watts Bar) there have been no nuclear reactors buit in the US for decades. Therefore the required and desired domestic infrastructure is limited at best (primarily to support the Navy Nuclear Program).) Avanced reactors (SMRs or Micro) all assume significant utilization of modular construction and factory assembly of components and/or complete reactor modules. Although there are aspects of "factory construction" for modules of some of the modern commercial reactors (e.g., AP-1000 and EPR), factories for the construction of entire rectors, such as for some SMRs and microreactors do not currently exist. Although not in the same category/scale as "factory costruction" for components or full reactors, there are demo-type facilities for commercial-level fabrication of TRISO fuel by X-Energy at ORNL, and a "restart" of TRISO fuel fabrication at BWXT (plus some deals between BWXT and GEH).

- The broad categories of non-LWR advanced reactor concepts include a variety of coolants, e.g., liquid-metal, gas-cooled, and molten salt (both for coolant and fluid fuel), fast, intermediate, and thermal-spectrum systems, and power levels from $<300 \mathrm{MWe}$ (SMRs) down to Microreactors $(<20 \mathrm{MWth})$. Although there has been some limited operating experience with some of these systems, few have been in a commercial context and scale (e.g., Peach Bottom and Ft. St. Vrain HTGR gas-cooled in the US, BN-600 and BN-800 SFRs in Russia).

- As a result, is there a need for a prototype/demo for some proposed concepts intended for commercial application? Since proposed concepts span a broad range of systems, this might be required for licensing and to reduce risk for commercialization. Since proponents hope to be the dominant player in whichever market they plan to play in, there is a strong incentive to preserve intellectual property and it istherefore difficult for the government to fund research and development that would benefit multiple concepts as it did in the early days of nuclear power unless there is a focus on overcoming common technical obstacles. The government has been supporting/funding development of several individual advanced reactor concepts via various mechanisms (see Section 4.2).

- Access to sufficient High-Assay-Low-Enriched-Uranium (HALEU), i.e., up to 20 w/o U235 is required to sustain a commercial scale enterprise of many proposed SMRs/Micro and many nonLWR advanced concepts (currently commercial fuel fabrication is limited to $<5 \mathrm{w} / \mathrm{o}$ U235). This would require a commercial enrichment capability that could produce the fuel and at the rquired scale to support a significant advanced reactor enterprise requiring HALEU; currently DOE is the only source of HALEU, and this may be limited in scale.

- Demonstration of claimed significant safety benefits for advanced reactor concepts relative to current commercial reactor (e.g., pasive safety) will likely be challenging without developing demonstration reactors to confirm performance claims.

\subsection{Safeguards, Security and Proliferation-related Issues}

The current frameworks for safeguards and security of nuclear energy systems are based mostly on LWR experience. The requirements for physical protection of facilities and information security, together with those for material control and accounting (MC\&A), constitute the primary elements of the NRC's special nuclear material (SNM) safeguards program. 
Next generation nuclear power systems have new design features and technologies that may require new tools and measures for safeguards and security that are different from those for a large LWR. For example, there may be issues associated with the fuels such that the existing accountancy tools and measures may need to be modified or further developed for reactors using non-conventional fuel types, such as, particle fuel in a high temperature gas-cooled reactor (HTGR), fluid-fueled molten salt reactors, and mixed fuel (uranium and plutonium) in a fast reactor. Further, issues may arise about new fuel loading schemes, as reactor cores with extremely long lifetimes may require innovative surveillance tools and measures, and long-life sealed core replacement may present novel accountancy challenges.

The trend of building future reactors with inherent safety and security features as well as accommodations for effective and efficient safeguards highlights the importance of considering interfaces of safety, security and safeguards at all stages of the life cycle of a nuclear plant. A challenge to integrate safety, security and safeguards $(3 \mathrm{~S})$ is to identify $3 \mathrm{~S}$ interfaces to enable the optimization of synergistic effects and the minimization of potential conflicts. It is feasible to realize cases in which measures intended to improve safety could have a negative effect on security, or vice versa.

Advanced reactor developers that are targeting potential deployment in the international arena will need to be aware of and responsive to IAEA (International Atomic Energy Agency) safeguards requirements. Safeguards-by-design (SBD) is generally recognized as an approach wherein international safeguards are fully integrated into the design process of a nuclear facility - from initial planning through design, construction, operation, and decommissioning. Methods addressing the technical aspects of proliferation resistance have been developed, most notably the Proliferation Resistance and Physical Protection methodology (PR\&PP) (GIF 2011) of the GEN IV International Forum (GIF). The PR\&PP evaluation could be an integral part of the SBD process, to elucidate the interactions between the intrinsic features (physical design features that impede proliferation, sabotage or theft) and the extrinsic features (institutional features that relate to States' commitments, obligations, and policies regarding nuclear nonproliferation ), study their interplay, and then guide the path toward an optimized design. The GIF PR\&PP Working Group is implementing an SBD process to evaluate the GEN IV system designs (Cojazzi, Cheng, and Renda 2018, Cheng 2019).

\subsection{The Economic Environment}

A brief review of the market structure wherein nuclear generators operates, and the evolution of that market frame the barriers in the economic environment facing the nuclear industry today. The two primary forces impacting the industry today are the competitive forces of the market and the policy measures imposed.

The decisions made to invest in the majority of the LWRs that make up the fleet today were done under a market regime that has changed substantially. In earlier days, the power industry was vertically integrated; in a specific geographic region a single public utility owned and operated power generation facilities, and infrastructure for transmission and distribution. This primary economic model of the day meant that the public utility was de facto a monopoly firm (Pineau, Rasata, and Zaccour 2011). Because of the utility's ownership of these assets the firm was what economists call a 'natural' monopoly and, without a government role in the market, the utility could exercise monopoly pricing power. To correct this market failure - a term that describes a situation where the value to society is mismatched with the cost to society - government regulation prescribed a pricing structure the utility had to follow. Implemented on sound economic principles, regulation both defended consumers against monopoly pricing and guaranteed utility investors a constant rate of return on capital investments (De Meio Reggiani et al. 2019). Vertical integration and regulated natural monopolies in the power industry created the objective for firms to meet demand at the lowest cost with the highest reliability, an objective that tended to create overcapacity (Pineau, Rasata, and Zaccour 2011). Moreover, this structure created key outcomes that factored into decision making around the business case for investments in nuclear power. 


\section{Retrospective analysis of LWR technology: lessons for today}

May 15,2020

XXV

By guaranteeing a revenue stream, market regulation mitigated much of the uncertainty that prevents industry expansion today. It was a contract, so to speak, between governments and firms (De Meio Reggiani et al. 2019).

The dominant, vertically integrated model that was the norm during the buildup of the LWR fleet changed with congressional reforms in the late 1970s that modified that structure. The Federal Energy Regulatory Commission (FERC) created a structure for utilities and independent power producers (merchant generators) to trade power at market based rates (Greenfield and Kwoka 2011). This unbundled the vertically integrated structure in much of the US. It introduced separate pricing for generation, transmission, and ancillary services. Later FERC ordered that all transmission owners yield control to their local RTO (Regional Transmission Organization). RTOs became the balancing authority through whom electricity was to be exchanged in both real-time energy markets and day-ahead, forward markets (Greenfield and Kwoka 2011). With this change, owners of generating capacity under the revised structure no longer had a guaranteed revenue stream, instead revenue and prices were determined by generators' production and market conditions (Pineau, Rasata, and Zaccour 2011). In markets where it occurred, de-regulation brought about a change in market structure that changed the business case for owners of nuclear generators, an issue that many financially-vested parties in the industry are still grappling with today (Szilard et al. 2016). Today approximately one-third of electricity is traded in regulated markets (Cleary and Palmer 2020).

\subsubsection{Re-structured Markets}

One of the first effects of re-structured markets on owners of nuclear power plants is what economists call the 'hold-up' problem. In the context of investments in nuclear generating capacity, it results from a change in the market arrangement from the prevailing arrangement at the time the investment was made. The forecasted, expected returns for large scale, long-term investments changed because the market structure changed. Once expenditures for the power plant were made, which investments are called are sunk costs because power plants cannot be sold for other purposes or moved to more favorable markets, then investors are constrained to operate in the power market that the reactor serves. With de-regulated markets investors were 'held-up', that is forced to accept the market changes "or else" shut down the plant. That is, because expenditure for the power plant was already made, investors had to accept lower prices in the de-regulated market. Investors in nuclear faced a hold-up from system operators in the RTO - investors could accept lower prices or go out of business (De Meio Reggiani et al. 2019).

A follow-on effect was that the objective of meeting demand at the least total system cost shifted to maximizing individual profits subject to the operating constraint of the de-regulated power market. This caused a change to issues impacting the business case for nuclear investment. Now, realities such as marginal cost pricing, financial risk management, unit commitment, short and long-run coordination, strategic bidding, market design, and capacity expansion planning all play into the economics of investment into nuclear power (Pineau, Rasata, and Zaccour 2011). Recent studies have identified the important role of alternative market access, for example industrial process heat, for the economics of investment in nuclear power to pencil out (Bistline, James, and Sowder 2019, Bistline and Blanford 2020). Additional revenue streams may arise from RTO compensation to nuclear generators for ancillary services such as spinning reserve and reactive power (Greenfield and Kwoka 2011). But if the hold-up problem and a changed operating objective were not enough, two other issues present significant challenge to nuclear competitiveness: mishandled externalities and low natural gas prices.

\subsubsection{Externalities}

Externalities are said to exist when benefits (positive) or costs (negative) accrue to people outside of a transaction. As such, they are also a form of market failure, as the market can only optimize those costs 
and /benefits that are within the market, resulting in a sub-optimal solution for the total system. When the government chooses to exert a policy aimed to correct market failure secondary impacts, those beyond the scope of the policy, can result that in some cases cause worse problems than that which the policy aimed to correct. This is the case with policies aimed to incentivize expansion of variable renewable energy technologies. Internalizing a negative externality (e.g. carbon emissions) with one solution has distorted electricity markets in a way that jeopardizes the positive solutions provided by other non-emitting sources such as hydroelectric and nuclear generators. The intermittent nature of electricity generation from variable renewables also creates a second problem, disrupting baseload generation from nuclear (GAO 2015). In this case picking one technology solution to incentive for clean energy production caused secondary effects that has exacerbated disruptions for solutions that also create clean energy. Policies such as the Renewable Portfolio Standard, and others like it, that mandate a certain fraction of power production from variable renewable generators, independent of system costs, also cause pricing distortions (e.g. negative prices) (Bistline, James, and Sowder 2019). The combination of increasing variable renewable penetration, intermittent supply from it, and the lack of policies that internalize positive externalities in nuclear power (e.g. reward nuclear generators for value created) generation is a key barrier to industry expansion today (Bistline, James, and Sowder 2019). The lack of comprehensive climate policy that internalizes externalities from carbon emissions is one of the leading reasons that prevents investment in nuclear technologies (Deutch et al. 2016). Recognizing the important role of nuclear power in a clean energy future, a few states, e.g. New York and Illinois, have started polices aimed at leveling the playing field of climate policy (Collins and Mason 2016). Recognizing the treatment of externalities as a barrier to nuclear power today, Buongiorno et al. (2018) suggest that policies should create a "level playing field" across low-carbon generating technologies.

\subsubsection{Natural Gas Prices}

Low natural gas prices are another competitive force that has been a barrier to an expanding nuclear industry. These low prices have been a source of lower average electricity prices (Collins and Mason 2016), and low electricity prices put significant competitive pressure on nuclear generators. Figure 7 illustrates the impact of low natural gas prices on nuclear economics. Suppliers of natural gas offer the highest bid price into the electricity market. That is, the short run marginal cost of producing natural gas acts as the market clearing spot price in the electricity market. The area labeled "Lost PS" illustrates the financial impact to nuclear generators. Producer surplus measures the level of additional or "surplus" value a supplier attains above the variable costs of production. Producer surplus less fixed costs is the supplier profitability. When natural gas prices fall, shown with the dotted line, generator producer surplus falls. This creates economic difficulty for nuclear generators to cover fixed costs. Economic pressure like this has been a leading driver in early retirements of nuclear generators (GAO 2015). In simulations, Bistline, James, and Sowder (2019) find that, in the presence of low natural gas prices, nuclear generators must find additional revenue streams to support a strong business case. In recent analysis from the Energy Information Administration (EIA), analysts reported in the recent Annual Energy Outlook that in the presence of low natural gas prices the share of electricity from nuclear generation could from could drop from a current $19 \%$ to $12 \%$ by 2050 (EIA 2020a). However, in the presence of high natural gas prices the projections show the share of electricity from nuclear generators to remain constant (EIA 2020a).

Natural gas prices depend on oil and gas production. Recent events in the oil market, and the accompanying historic low prices, suggest that the significant competition from low natural gas prices may lessen. Because natural gas is produced in conjunction with oil, and if oil production falls, the supply of natural gas could also fall. This reduction in the supply of natural gas has the potential to put upward pressure on the price of natural gas. 


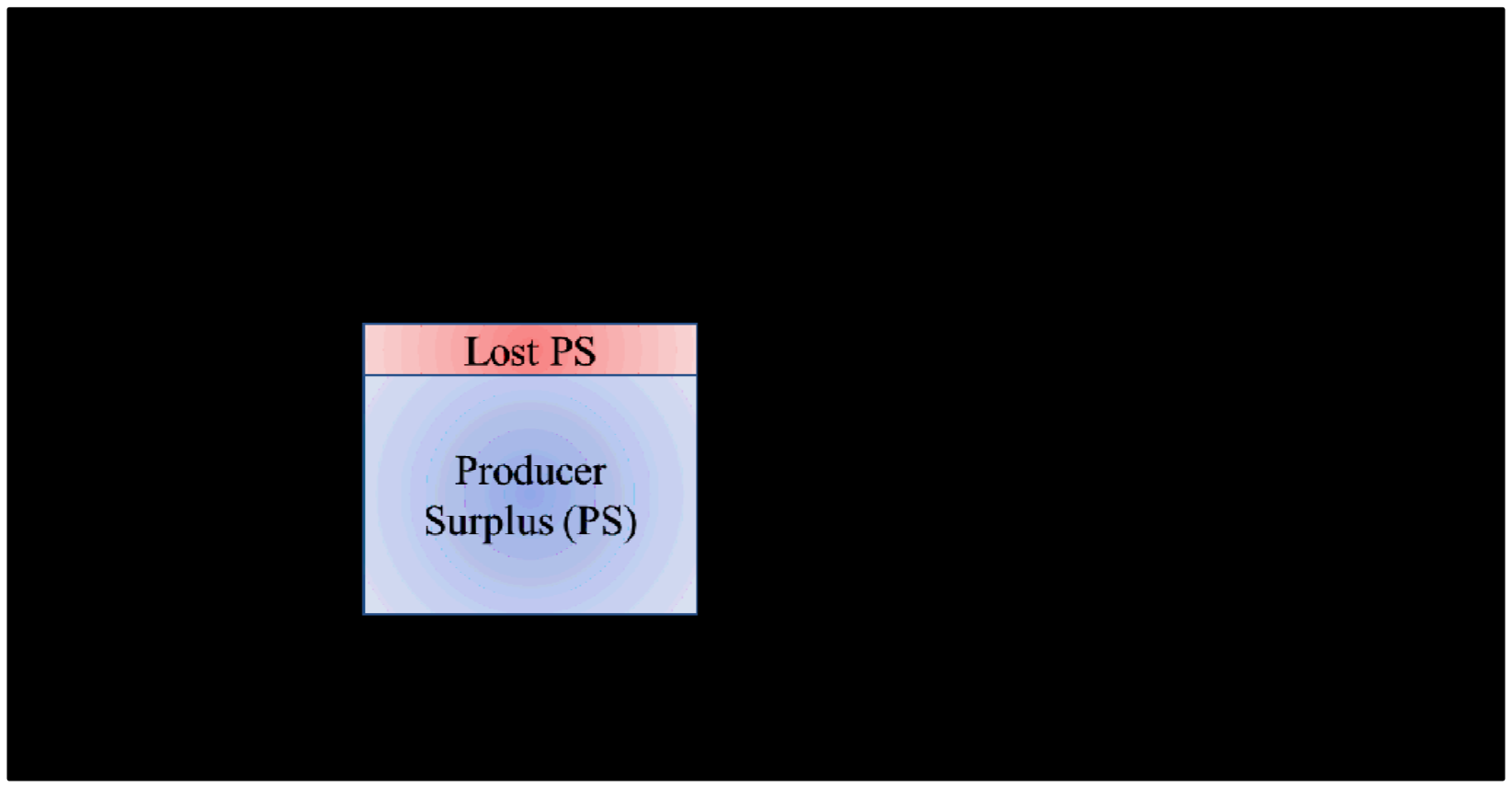

Figure 7 Illustrating impact of lower natural gas prices

\subsection{Public Perception}

Byrne and Hoffman (1996) observe that the single most consistent predictor of whether a society will embrace a large megaproject like a nuclear reactor is the ability to think of important needs in the future. This observation somewhat ties to the finding in Jewell (2011) that a civilian nuclear program can find support in even poor countries if the program is connected to a military defense and weapons program. Rangel and Lévêque (2015) write that in highly developed countries, where civilian nuclear is of interest to policy makers, investors, utilities, and the public at large the cost of nuclear and associated construction costs are of paramount concern.

Nuclear power leads to a diversity of public opinion; it perhaps generates the most variation in public opinion of any power generation type (Ahearne 2011). For example, in 1994 a US Gallup poll found that $57 \%$ of survey respondents favored nuclear energy and by 2015 those stating favor towards nuclear power fell to $51 \%$ (van de Graaff 2016). More recently, Gallup found that Americans are evenly divided on nuclear energy at 49\% each (Reinhart 2019). However, when viewed based on political party the results change: $65 \%$ of surveyed Republicans support nuclear energy while only $42 \%$ of Democrats support it.

A large driver behind the opposition is a lack of public trust and the way that people perceive, understand and respond to risk (Bisconti 2018, van de Graaff 2016, Kahan, Jenkins-Smith, and Braman 2011, Sunstein 2002). As researchers look deeper into this finding one result that emerges is that despite efforts to educate the public, proponents could do a better job to engage with a cross-section of opinions (van de Graaff 2016). During the period of the hoped-for nuclear renaissance, this difference of perception was a leading driver of public sentiment.

Opinion, favorable and non-favorable to nuclear power, disaggregates along different dimensions. The primary bifurcation exists in issues related to the nuclear energy promise versus peril (Bisconti 2018, Starr 1969). Further, research on public opinion finds that both perspectives exist in society's thoughts towards nuclear energy. The favorable perspective towards nuclear is shaped by concerns over energy 
security or shortages, no nuclear accidents or incidents, conflict in the Middle East, respected political leaders who favor nuclear, hope for a nuclear renaissance, the excitement of new plants under construction, and climate change. Of people favoring nuclear energy, $28 \%$ choose that based on positive environmental benefits and anticipated low energy cost of nuclear (Bisconti 2018). Negative public opinion is rooted in nuclear accidents or incidents, abundant energy supplies, opposition from popular political figures, focus on nuclear waste, power plant shutdowns, and the perception that renewables are a sufficient energy source (Bisconti 2018).

\subsection{On Time and On Budget}

Singular to the barriers present in the economic environment, and based on modeling and simulation, Bistline, James, and Sowder (2019) recognize that for advanced nuclear concepts to be competitive in the marketplace new nuclear construction must be built at lower costs. Sovacool and Cooper (2008) find that in China, France, India, Japan, the former Soviet Union, the U.S., Spain, and Canada technology optimism and vision of what nuclear energy can provide overrides concerns about costs. However, Bistline, James, and Sowder (2019) recognize that long and uncertain construction times, uncertain costs, financing and project performance are leading contributors to high construction costs, notwithstanding optimism of benefits nuclear technology can provide. This subsection summarizes known barriers to new nuclear construction being built on time and on budget.

\subsubsection{Management Issues}

Buongiorno et al. (2018) describe failures of management as one of the leading factors that contributes to cost overruns in the nuclear industry today. They describe cost overruns from nuclear projects in the United States and Europe then link these to management failures. These arise from lack of flexibility in how to carry out project work. Biegal et al. (2019) describe a similar finding, noting that lack of expertise in contract management over large projects is a source of cost overruns. Further, Biegal et al discuss the importance of aligning incentives across all agents in the contract to improve contractor performance. These studies identify issues that arise in project management as central to the causes that lead to project delays then cost overruns. Biegal et al. list the following as the major sources of management issues: project planning and controls, managing team attributes, managing stakeholder concerns, and managing key information needs across the project. This is consistent with Ahearne (2011) who finds that efficient project management and good quality control are necessary to achieve faster construction times, especially since the industry is currently plagued with weak management.

\subsubsection{Cost Estimation Error and Bias}

Error in estimating project costs in the nuclear industry has been a barrier to studies for some time. Beginning with analysts at RAND (Merrow, Chapel, and Worthing 1979, Merrow, Phillips, and Myers 1981), studies have investigated over-optimistic cost estimates. Also with RAND, Zimmerman (1982) observed similarly. These reports provide a quantitative analysis of how cost estimates evolve over the lives of large projects, from a conceptual stage to the finalized cost once complete. These errors are based on two primary sources: estimating error and psychological biases (Biegal et al. 2019). Estimation errors arise from analyst's treatment of uncertainty while psychological issues in estimation error arise from biases due to inherent project optimism and initial-estimate anchoring. These sources of error lead to a consistent result: overestimates of the benefits and underestimates of the costs (Byrne and Hoffman 1996, Sovacool, Gilbert, and Nugent 2014, Buongiorno et al. 2018).

\subsubsection{Financing Delays}

it is possible that the need to secure further financing after the under-estimated budget is exceeded can delay construction and escalate costs further; however, there is no analysis on this. Some empirical evidence can be drawn from the recent attempted expansion of the South Texas Nuclear Project. In 2007, 


\section{Retrospective analysis of LWR technology: lessons for today}

May 15,2020

xxix

NRG Energy filed an application for two Toshiba ABWRs to be added to the site (currently containing two PWR units). The estimated cost for the expansion was around $\$ 13$ billion (including financing cost). However, in 2009, Toshiba provided a cost estimate that was $\$ 4$ billion more than the original estimate (Power 2009). This caused CPS Energy, who had a 50\% stake in the project to reduce their shares to $7.625 \%$ as well as to halt paying money into the investment (Souder 2010). In 2011, NRG Energy announced that it would halt further investment into the project (NRG 2011).

Buongiorno et al. (2018) described the significant incentive that project financing places on construction projects to finish as soon as possible. Interest rates in recent years have been historically low, so if currently delayed nuclear projects had been forced to deal with higher interest rates during project delays the financial impact could have been far worse. The observation by Buongiorno et al.is consistent with what the literature has to say regarding project lead times - the longer the lead time the less competitive the project will be due to the finance costs (Sovacool, Gilbert, and Nugent 2014, Csereklyei et al. 2016). Thurner, Mittermeier, and Küchenhoff (2014) go so far as to say that poor prediction of lead time impacts the financial interests of owners and operators, although this is a problem not exclusive to nuclear construction. They arrive at this conclusion because lead time impacts when the first positive cash flow occurs, and thus when construction interest ends, and repayment begins. Similarly, Mari (2014) finds that one of the main financial risks facing project success is the large, upfront capital investment and the uncertainty regarding the time that repayment begins. Industry development is critically dependent on financial structures to support nuclear projects (Burke 2013).

\subsubsection{Incomplete Designs and Over-specified Designs}

Carter (2017) states that incomplete nuclear power plant designs leads to project "scope definition deficiency." This can cause budget and schedule inaccuracies. A recent example of that occurred with construction at Vogtle, where significant effort of rework was required, due to the design issues at Vogtle 3 (Pavey 2012) and sub-module rework (Judy 2013). The newspaper articles do not show specific and quantitative analyses indicating the exact increase in cost of the construction. Wright et al. claim that rework makes up a large component of cost and schedule overruns (Wright, Cho, and Hastak 2014) and even claims that it historically amounts to $12 \%$ of the overall project cost. Turek shows how the cost overruns from delays, potentially caused by rework, can be magnified by the interest accrued during the delay (Turek 1995).

\subsubsection{Work Force Issues}

A somewhat intuitive finding is that nuclear projects located in states where construction wages are higher cost more (Cantor and Hewlett 1988). This bears on where nuclear plants may be sited in the future, especially because labor can account for as much as two-thirds of the costs of a nuclear construction project (MacDonald 2011). This could especially be an issue in modular construction if the prevailing wage rate is not commensurate with labor productivity in the area (Buongiorno et al. 2018). A further complication to labor costs is the impact of construction lead times. As lead time increases, an issue arises where labor has to be released then called back, adding to cost, especially when pressure exists to shorten lead times (Cantor and Hewlett 1988). This results from un-planned effort that must be used up to find qualified labor on short notice.

Sovacool, Gilbert, and Nugent (2014) describe how labor was part of the issue facing the Washington Public Power Supply System (WPPSS). Based on projections for continued increase in energy demand beginning in the early 1970's, WPPSS placed an order for seven nuclear reactors. But faced with the backlog of nuclear construction across the country, nuclear qualified labor (architects and engineers) was scarce. This led to problems of plant design, poor craftsmanship, labor strikes, and longer lead times - all of which added to cost. Focusing primarily on lead times, Thurner, Mittermeier, and Küchenhoff (2014) 
point out that labor wages is the variable expense most sensitive to increased lead times. However, it is unclear if it was the lead time directly or some other correlated event that impacted increased labor costs. Increased lead times, it turns out, depresses the morale of nuclear construction workers (Cantor and Hewlett 1988), and has been found to be a contributor to cost drivers in the U.S. (Braum 1984).

\subsubsection{Supply Chain Atrophy}

Supply chain atrophy is a leading cause of escalating costs in the US nuclear industry (WNA 2017a, b, MacDonald 2010, Du and Parsons 2009). With the announcement of construction suspending at VC Summer, there was not enough remaining demand and ongoing work to gain economies of series in supply chain logistics (WNA 2017b). This leads to little incentive to invest in the nuclear construction supply chain and thus more atrophy. This can be a significant problem if many firms are contributing to a nuclear construction project and independently trying to manage their own supply chains (Ruuska et al. 2011). An example of this is the bottleneck in large forgings and thick rolled plates as reported from 2010 (MacDonald 2010). Second, it increases the uncertainty in the supply chain's ability to deliver quality products on time. This uncertainty will cause investors to charge a higher risk premium (MacDonald 2010). Finally, less demand limits "production" of experienced project managers and skilled labor (MacDonald 2010, Schimmoller 2008, WNA 2017a)

In addition to atrophy, the nuclear construction supply chain has experienced cost escalation faster than inflation (Rangel and Lévêque 2015). Commodity prices, being well-documented, increased 35-45\% between 2002 and 2007 compared to generation inflation which rose at $16 \%$ over the same time frame. The price of engineering services increased over this time period as well (WNA 2017b). 


\section{Retrospective analysis of LWR technology: lessons for today}

May 15,2020

xxxi

\section{LWR History Lessons Learned}

This section provides lessons learned. These are based on comparing the narrative of LWR development with barriers that face the industry today.

\subsection{Lessons by Application}

\subsubsection{Lessons to Apply in the Economic Environment}

- LWR technology succeeded because those who promoted it had a defined problem (national security) they were seeking to solve. The technology was 'pulled' into development to solve a problem then 'pushed' into another area (civilian power) where it created value.

- Industry investment in new technology is proportional to the expected payoffs from the investment and the perceived risks; this economic principle presents itself in actions of early corporate involvement in the nuclear industry.

- First-movers in an industry bear risks that generate positive externalities for firms that follow. The Role of the "Government" in bringing a new technology to market is to offset first-mover risks.

- Technology adoption depends on faster movement along the learning curve, relative to competition. The more that is known about a technology early in its development, the more that technology edges out new entrant technologies for which less is known.

\subsubsection{Lessons to Apply in Current Policy and Regulation - Government Role}

- Capacity to regulate civilian power in the US developed alongside of LWR technology itself; development in regulation goes hand-in-hand with development in technology.

- Policy support is a function of public perception; policies reflect majority of public perception. When public opinion rallies around a central issue of concern then policies reflect that issue.

- Because of the important role of learning in technology adoption, new knowledge should be captured and shared in a way that others generating new technology can apply it.

- Congressional support, like that gaining traction today e.g. Advanced Reactor Demonstration Program, is not without precedent, it was instrumental for initial development.

\subsubsection{Lessons to Apply in Marketing Developing Technologies Internationally}

- With respect to exporting nuclear technology, domestic manufacturers should negotiate localization and technology transfers in the technology sale.

- The diffuse ownership of reactor companies in the past may suggest that emerging new designers and developers of advanced reactors may want to consider a similar approach of cultivating mutually beneficial partnerships with countries and organizations to which they transfer their technologies.

\subsection{Lessons by Description}

- LWR technology succeeded because those who promoted it had a defined problem (national security) they were seeking to solve. The technology was 'pulled' into development to solve a problem then 'pushed' into another area (civilian power) where it created value. 
This suggest that in today's environment new technologies will have a higher potential to be economically viable if they can be 'vetted' in another industry outside of civilian power. Pioneering efforts in LWR technology development in submarine propulsion applications were pivotal in generating knowledge that could be later leveraged in civilian power.

- Industry investment in new technology is proportional to the expected payoffs from the investment and the perceived risks; this economic principle presents itself in actions of early corporate involvement in the nuclear industry.

Firms are more willing to engage in research and development with increasing demand for new technology or as costs of developing new technologies fall. This gives rise to three industry $R \& D$ approaches: 1) delay investment until the costs of applying new technology fall sufficiently for expected payoffs to rise, the loss-leader incurs the financial risks of demonstration, 2) incrementally develop technology so to mitigate investment risk that expected payoffs fall below critical threshold, a riskmitigating strategy but one that leads to lengthy technology development, 3) pursue multiple technology options at a single time so to increase the chances that at least one of the investments have a sufficiently large payoff, diversification through hedging but significant financial backing required.

Strategy (1) is observed in the relationship pattern between the US Government and nuclear industrial firms Westinghouse and GE. The majority share of investment in initial LWR technologies applied to US Nuclear Navy were born by the US Government with these two firms as active participants. At the government's expense, these firms learned much about how LWR technology works. By engaging US industry, the US Government overcame the investor incentive of second-mover advantage - let someone else figure out all the flaws then apply it (Margaria 2019) - which enabled these two firms to have a firstmover advantage in building civilian nuclear power plants. This is further borne out by the choice of Westinghouse and GE to offer turnkey contracts, at financial loss, on initial orders, continuing to gain learning about the technology, and solidifying their first-mover advantage observed in construction orders following the turnkey period. Strategy (2) can be seen in the IPP where multiple components of technology were investigated. Strategy (3) is observed int eh CPRDP program where the government can be thought of as investing in multiple technologies at once.

- First-movers in an industry bear risks that generate positive externalities for firms that follow. The Role of the "Government" in bringing a new technology to market is to offset first-mover risks.

Industry is unlikely to bear the full costs of new nuclear technology without a relatively strong and certain expected payoff. Like demonstrations programs of the past, the US Government can offset these early risks to enable industry research and development. In the CPRDP project, an early public-private demonstration program, AEC funded about $46 \%$ of the total investment costs. In the early phases (test reactors) of demonstration programs, government mostly built the projects with private sector involvement in design, engineering, and construction. As demonstration proceeded to small and large demonstration reactors, private sector involvement increased to the point that by large demonstration, the private sector was largely responsible for project leadership.

Government involvement and support played a key role in the development of the current LWR-based commercial nuclear power industry as described earlier. There have been significant recent efforts by the government to support the nuclear power industry, and especially the development of advanced reactor concepts, including loan guarantees, several Funding Opportunity Announcements (FOAs), the Gateway for Accelerated Innovation in Nuclear (GAIN) program and now the National Reactor Innovation Center (NRIC) to connect industry to capabilities at the national labs to support development of advanced reactor concepts. There is significant funding proposed for two advanced reactor demonstration projects, and funding to support up to 5 proposals for "risk reduction". 


\section{Retrospective analysis of LWR technology: lessons for today}

May 15,2020

xxxiii

The above efforts are like the role of the AEC in the early days of supporting the demonstration of proposed concepts and the down select to the most "promising" where they were then commercialized by industry. In the current environment where tens of concepts are being developed, many (most) funded by investors who hope to have a significant market niche. The protection of intellectual property makes many proponents leery of participating in the government funded projects for fear that the selection process will de facto do the down select.

These efforts demonstrate obvious congressional support as evidenced by the proposed funding, but this level of commitment and support may not be sustainable in the long-term as was the case with the JCAE which had an intimate role in supporting the development of nuclear power in the US.

- Technology adoption depends on faster movement along the learning curve, relative to competition. The more that is known about a technology early in its development, the more that technology edges out new entrant technologies for which less is known.

Given two technologies, (A) and (B), the success of either in terms of adoption in the marketplace depends on how quickly one technology moves along the learning curve relative to another. Suppose (A) is applied before (B). Learning about (A) takes place, learning by doing and learning about payoffs. Meanwhile, even if (B) on paper appears superior to (A), learning about (A) increases the switching costs to (B). For the next application more is now known about (A) than (B), even if (B) remains superior on paper. The cost for applying (B) continues to increase relative to applying (A) and due to uncertainty in the unknown (B) versus the more understood (A) and because of risk aversion. (A) is once again applied and technology "lock-in" occurs - applications are now locked-in to what (A) can provide.

This pattern is observed in Rickover's initial choice of LWR over alternative nuclear technologies that might have worked for powering US Navy submarines. Subsequent applications of nuclear technology for military applications of propulsion rested upon what was learned about how technology performs operationally and from a safety perspective on previous applications of the technology. The uncertainty associated with switching to a non-LWR alternative exceeded the potential benefits, e.g. the GE's sodiumcooled reactor technology on the Seawolf was replaced by the better-known Westinghouse's light watercooled reactor technology applied on the Nautilus. The connection to military and national security is still a potential "driver" for the potential "success" of some advanced nuclear systems. The supply chain required by the Nuclear Navy provides an infrastructure that can potentially support some new initiatives in micro reactors by $\mathrm{DoD}$, and for space (power and thermal propulsion), but infrastructure required to support a "robust" advanced reactor industry base on SMRs and/or microreactors does not exist. The infrastructure required to support large-scale construction of commercial nuclear plants, either LWR or non-LWR does not exist domestically.

- Capacity to regulate civilian power in the US developed alongside of LWR technology itself; development in regulation goes hand-in-hand with development in technology.

As issues related to safety came about in applications of LWR for civilian power, regulatory authorities learned about the technology and developed regulatory protocols in response to issues as they arose. This led to technology lock-in on the part of the regulator and regulator learning about LWR technology. Involving the regulator in the characteristics of non-LWR concepts may avoid regulatory hurdles latter on as technology moves closer to market, and significantly reduce the time and effort required for the licensing process.

There have been many attempts over the years to develop "technology-neutral" approaches for licensing of non-LWR reactors (Samanta 2019, 2020). More recently, there is an ongoing effort to address these challenges via a proposed approach to a rulemaking to develop the regulatory infrastructure to support the 
licensing of advanced nuclear reactors. This rulemaking would revise the U.S. Nuclear Regulatory Commission's (NRC's) regulations by adding a risk-informed, technology-inclusive regulatory framework for commercial advanced nuclear reactors in response to the Nuclear Energy Innovation and Modernization Act (NEIMA).

- Policy support is a function of public perception; policies reflect majority of public perception. When public opinion rallies around a central issue of concern then policies reflect that issue.

Atoms for Peace is an example of this. Because of the Soviet Union's choice to detonate an atomic bomb, US policy makers were able to capitalize on public concerns of Soviet leadership and superiority. The beginning of the civilian power industry, Shippingport Atomic Power Station, was made possible because of US government interest to increase international security through domestic leadership.

Public support such as in the days of the Cold War is no longer a given. There is significant anti-nuclear sentiment as a result of accidents like TMI, Chernobyl and Fukushima (as well concerns over safety and what to do with the waste), and the feeling that nuclear is not needed now or for the future given the promise of renewables. The role of cheap natural gas and lobbying of proponents for non-nuclear approaches to climate change or other objectives has impacted attempts at the state-level and internationally to support existing nuclear plants and further development of nuclear power.

- Because of the important role of learning in technology adoption, new knowledge should be captured and shared in a way that others generating new technology can apply it.

This is tricky because firms will need to have a strong expected payoff to engage in development, so some provision should be made for pioneer investors willing to take on early technology risks. But if competition is the aim, industry participants should be able to take advantage of knowledge created at government expense. Otherwise technology lock-in will occur again and the few investors early on will be those who capture the market - and further innovation is constrained.

- Down-select leads to technology "lock-in" but lock-in is in fact necessary for industry progress.

Parallel development of a multitude of designs while desirable in the early stages of technology development, to uncover the merits and limitations of each technology, is not a strategy that can be pursued indefinitely. Market forces alone may not be able to achieve a down-selection and intervention or stewardship by the state may be desirable or necessary. Now, the industry finds itself with several concepts ready to move forward. The major lesson of the LWR experience is that the concept that eventually does dominate ought to be one with a broad range of applications.

- Congressional support, like that gaining traction today e.g. GAIN and NRIC, is not without precedent. It was instrumental for initial development.

When the AEC reduced extensive subsidy, programs offered for support of new commercial reactors, and under persuasion from utilities and nuclear manufactures, Congress appropriated \$20 million in 1961 for subsidies to nuclear construction. This was a critical step to break the 'grid-lock' that the industry faced at the time. Then, new construction at Connecticut Yankee and San Onofre 1 were beneficiaries of this new program and AEC financing. These reactor projects led the way to The Turnkey Era when US manufactures then found potential gains worthwhile to offset financial risks.

Government "subsidies" to competing energy generation systems and regulated vs. non-regulated utility markets have a significant impact on the viability of nuclear concepts (beyond possibly "niche markets" like remote locations) in the current US energy mix.

- With respect to exporting nuclear technology, domestic manufactures should negotiate localization and technology transfers in the technology sale. 


\section{Retrospective analysis of LWR technology: lessons for today}

May 15,2020

XXXV

Many advanced reactor concepts, particularly small modular reactor designs, are envisioned as "drop-in" systems that can be manufactured in a factory and deposited at the site of use. However, to the degree that the designers and developers of these reactors have export ambitions, they would do well to note that even today, buyer countries may institute localization and technology transfers as preconditions to purchases of reactor technology. As a result, companies aiming to produce factory assembled monolithic systems would do well to reflect on approaches for decomposing these systems into smaller sub-units, some of which could potentially be manufactured and built in the buyer countries.

- The diffuse ownership of reactor companies in the past may suggest that emerging new designers and developers of advanced reactors may want to consider a similar approach of cultivating mutually beneficial partnerships with countries and organizations to which they transfer their technologies.

Reactor design projects are typically long-term and slow-moving efforts. Energy markets, however, can frequently be volatile and shifts in market conditions have the potential to impact the competitiveness of reactor designs under development. In such a situation the existence of multiple design variants under development in multiple locations, as has been the case for American reactors in the recent past, has made it possible for reactor vendors to pivot from uncompetitive to competitive designs for local markets in the face of changing market conditions. Absent the existence of alternate designs, pivots to serve new and changing markets are likely to be slower and therefore miss windows of opportunity. To this end, designers of advanced reactors, instead of focusing their efforts on a single design variant, may want to instead consider the simultaneous development of multiple variants in collaboration with international partners. 


\section{Summary and Conclusion}

This is a study that reports on lessons learned from the growth of LWR technologies. Researchers conducting the study reviewed historical documents published in government reports, peer reviewed journal articles, conference proceedings, books, national laboratory reports, and reports published by 'think-tank' type institutions. A few of these studies included lessons-learned, synthesis documents where the content is directly related to the growth of LWR. Other documents contained historical events and informed on the context underlying the events. From this detailed review, researchers constructed the LWR deployment timeline. Then researchers identified the major challenges facing the nuclear industry today. Comparing the events in the LWR history with current barriers generated lessons that can be used to help promoters of the nuclear industry overcome current roadblocks.

A significant take-away from this study, and a point made in earlier research, is that the government, by way of the US Navy, made choices early in the LWR development that led to technology "lock-in" (Cowan 1990), something economists call "path-dependency." The outcome of such a phenomenon involves a series of tradeoffs. Because of the significant amount of learning that took place about the LWR technology, both on the part of the military and especially on the part of US manufactures, later choices about nuclear technology were dominated by what was known about the LWR technology. Several programs geared towards evaluating alternative nuclear technologies were pursued, but time and again the LWR technology held the day. Consequently, what resulted was a nuclear industry oriented around, for the most part, a single technology. Some suggest this technology dominance prevented other technologies from gaining ground, and it may have. But on the other hand, because so much became known about LWR early on, the private sector found the potential payoff worth the pioneering risks taken to invest. Hence the tradeoff: LWR resulted in the dominant technology but had a single technology not been chosen then a robust nuclear industry in the civilian power market may not have emerged.

From this finding emerges an important insight for today's industry and those in government supporting it. The down select process plays a major role today and shapes the industry's progress. Had a single technology not been chosen it is hard to say how the industry would have developed. But what can be said is that because a single technology emerged, then industry, with profit motives and economic incentives, could develop. A further implication of these findings may be that paradoxically, progress in the nuclear energy sector in fact benefits from down-selection, lock-in and the emergence of a dominant design. Parallel development of a multitude of designs while desirable in the early stages of technology development, to uncover the merits and limitations of each technology, is not a strategy that can be pursued indefinitely. Lessons from LWR history also suggest that market forces alone may not be able to achieve a down-selection and intervention or stewardship by the government may be desirable or necessary. Now, the industry finds itself with several concepts ready to move forward. The major lesson of the LWR experience is that the concept that eventually does dominate ought to be one with a broad range of applications.

Another significant finding of the study is that early nuclear decision makers were faced with a welldefined problem to solve; find a way to apply nuclear propulsion for submarines. Solving this problem gave rise to a body of knowledge that had economic value in a completely different application. Although shortly after the dawn of the nuclear navy policy makers began looking at civilian power markets as a way for domestic expansion of a nuclear industry, civilian power was not the initial driving force of nuclear and thus LWR development. This suggests that for today, a well-defined problem with public support. Early on it was fear of Soviet nuclear dominance in the early 1950s, today it is the possibility that Russia and China overtake the US as global nuclear leaders (DOE 2020). Where advanced nuclear technologies and concepts provide a solution, will most likely be the critical first driver of breaking the industry and policy gridlock. Under current circumstances, a problem that may unify the efforts of the 


\section{Retrospective analysis of LWR technology: lessons for today}

May 15,2020

xxxvii

many actors involved in reactor development may be a desire to enhance geopolitical influence by rebuilding the domestic nuclear industry and developing reactors for export. Other unifying problems may be energy security, concerns about climate change, or integration of nuclear energy into a market heavy with intermittent renewables. The lesson from history is that when a problem facing the country is well-defined, when institutions are stable and in place to support its resolution, and when the private sector projects profitability from solving the problem, then economic forces will direct resources in a way that supports industry growth. GE and Westinghouse took on significant financial losses, initially, to break the gridlock facing the industry so that it propelled forward.

In conclusion, while this lessons-learned study has focused on LWR development from 1945 - 1970, i.e., from inception to commercialization, the trajectory of development of the LWR continued beyond this period of time. Technologies based on complex systems - of which nuclear reactors are the archetypal example - continue to evolve and improve even after the first commercialization effort. This phase of the innovation process is sometimes referred to as improvements in use and is a phase, which, if properly executed, can lead to significant improvements in the economic performance, operational characteristics, and reliability of a technology. Here too, there are lessons that can be learned from the LWR experience, which may usefully be applied in the near future to the development of advanced reactors. For example, better understanding of how applications of LWR technology in the presence of constraints such as waning public opinion and disruptions in the nuclear supply chain, both issues during the improvement phase of the early 1970s through 2000, will generate additional, key lessons for the advanced reactor industry. This phase was not limited to the US, instead it extended to partner nations engaging in trade of LWR technology. In a follow-on, ongoing study of these issues, a companion report to this lessonslearned study will outline lessons from international trade in LWR technologies. It is an important and timely area of future research.

Current nuclear plants are under economic stress in several markets, due in part to the economic environment, supply chain issues and incentives provided to other energy sources. Applying the lessons of the LWR history - strong government support for technology solutions to a defined problem, public support behind solving that problem, and stable institutions to induce market incentives - may help the nuclear industry transition to its phase, one of new nuclear concepts and advanced reactors. In the aviation industry propellers were the dominant airplane technology that met society's needs for a long time, but when needs changed beyond what propellers could provide, they did not go away. Instead, propeller propulsion technology provided a framework whereby jet engine propulsion could develop. The hinge point in the nuclear industry today is like that. Society's needs for nuclear technology are changing, but this does not mean LWR needs to go away. Like the aviation industry, what has been achieved in the development of LWR technology is the lifting off point from which new designs and advanced reactor concepts can takeoff. 


\section{Report References}

Adomaitis, Dennis, Gianfranco Saiu, and Mariano Oyarzabal. 1998. "European passive plant program: A design for the 21 st century." Nuclear engineering and design 179 (1):17-29.

Ahearne, John F. 2011. "Prospects for nuclear energy." Energy Economics 33 (4):572-580.

Amsden, Alice Hoffenberg. 1992. Asia's next giant: South Korea and late industrialization: Oxford University Press on Demand.

Averch, Harvey, and Leland L Johnson. 1962. "Behavior of the firm under regulatory constraint." The American Economic Review 52 (5):1052-1069.

BEA. n.d. "Gross Domestic Product." Bureau of Economic Analysis, accessed March 26. https://www.bea.gov/data/gdp.

Biegal, K., F. Ganda, J. Hansen, A. Curadra, and E. Hoffman. 2019. Cost Drivers for Construction of DOE Large-Scale Nuclear Facilities. Chicago, IL: Argonne National Laboratory.

Bisconti, Ann Stouffer. 2018. "Changing public attitudes toward nuclear energy." Progress in Nuclear Energy 102:103-113. doi: 10.1016/j.pnucene.2017.07.002.

Bistline, John E. T., and Geoffrey J. Blanford. 2020. "Value of technology in the U.S. electric power sector: Impacts of full portfolios and technological change on the costs of meeting decarbonization goals." Energy Economics. doi: 10.1016/j.eneco.2020.104694.

Bistline, John, Revis James, and Andrew Sowder. 2019. "Technology, Policy, and Market Drivers of (and Barriers to) Advanced Nuclear Reactor Deployment in the United States After 2030." Nuclear Technology:1-20.

Braum, Chaim 1984. "International Comparision of Power Plant Capital Costs." ANS/ENC International Conference, Washington, DC, November.

Buck, Alice L. 1983. A history of the atomic energy commission. USDOE Assistant Secretary for Management and Administration, Washington, DC ....

Buongiorno, J., J. Parsons, M. Corradini, D. Petti, R. Auguste, P. Champlin, K. Dawson, Z. Dong, C. Forsberg, A. Foss, E. Ingersoll, J. Lassiter, R. Lester, J. Lovering, L. Rush, N. Sepulveda, A. Umaretiya, R. Varrin, P. White, D. Whyte, and K. Yau. 2018. The Future of Nuclear Energy in a Carbon-Constrained World, MIT Energy Initiative. Cambridge, MA: MIT.

Burke, Paul J. 2013. "The national-level energy ladder and its carbon implications." Environment and Development Economics 18 (4):484-503.

Burness, H Stuart, W David Montgomery, and James P Quirk. 1980a. "Capital contracting and the regulated firm." The American Economic Review 70 (3):342-354.

Burness, H Stuart, W David Montgomery, and James P Quirk. 1980b. "The turnkey era in nuclear power." Land Economics 56 (2):188-202.

Byrne, John, and Steven M Hoffman. 1996. "The ideology of progress and the globalization of nuclear power." Governing the atom: The politics of risk 7:11-46.

Cantor, Robin, and James Hewlett. 1988. "The economics of nuclear power: further evidence on learning, economies of scale, and regulatory effects." Resources and Energy 10 (4):315-335.

Carter, James. 2017. "Learning from the Past, Part 1 - Start at the Beginning: Scoping and Engineering." 


\section{Retrospective analysis of LWR technology: lessons for today}

May 15,2020

xxxix

http://www.modus-group.com/learning-from-the-past-part-1-start-at-the-beginning-scoping-andengineering/.

Cheng, Lap-Yan. 2019. The GIF Proliferation Resistance and Physical Proection Methodology Applied to GEN IV System Designs: An Update. Brookhaven National Lab.(BNL), Upton, NY (United States).

Cleary, Kathryne, and Karen Palmer. 2020. "US Electricity Markets 101." Resources for the Future. https://www.rff.org/publications/explainers/us-electricity-markets-101/.

Cojazzi, Giacomo G, Lap-Yan Cheng, and G. Renda. 2018. "The GIF Proliferation Resistance and Physical Protection Methodology Applied to Gen IV System Designs: Some Reflections."

Collins, John, and Charles Mason. 2016. Summit on Improving the Economics of America's Nuclear Power Plants. Idaho Falls, ID (United States): Idaho National Laboratory (INL).

Cowan, Robin. 1990. "Nuclear power reactors: a study in technological lock-in." The journal of economic history 50 (3):541-567.

Csereklyei, Zsuzsanna, Paul W. Thurner, Alexander Bauer, and Helmut Küchenhoff. 2016. "The effect of economic growth, oil prices, and the benefits of reactor standardization: Duration of nuclear power plant construction revisited." Energy Policy 91:49-59. doi: 10.1016/j.enpol.2015.12.032.

De Meio Reggiani, Martin C., Miguel Vazquez, Michelle Hallack, and Nélida B. Brignole. 2019. "The role of governmental commitment on regulated utilities." Energy Economics. doi: 10.1016/j.eneco.2019.104518.

Deutch, John, Michael Greenstone, Shirley Jackson, William Madia, Richard Meserve, Dan Reicher, Joy Rempe, Gary Samore, Clay Sell, Phil Sharp, Steve Specker, and Joe Turnage. 2016. Secretary of Energy Advisory Board Report of the Task Force on the Future of Nuclear Power.

DOE-NE. 1980. US Central Station Nuclear Electric Generating Units: significant milestones. United States: US Department of Energy.

DOE. 2020. Restoring America's Competitive Nuclear Advantage: A strategy to assure US national security. Edited by US Department of Energy. Washington, DC: US Department of Energy.

Du, Yangbo, and John E Parsons. 2009. Update on the cost of nuclear power. MIT Center for Energy and Environmental Policy Research.

EIA. 2020a. Annual Energy Outlook 2020 with projections to 2050. Edited by US Energy Information Administration, Annual Energy Outlook. Washington, DC: US Department of Energy.

EIA. 2020b. "Annual Energy Review: Electricity Data." U.S. Energy Information Administration, accessed March 26. https://www.eia.gov/totalenergy/data/annual/index.php.

Finan, Ashley. 2012. "Energy system transformation: an evaluation of innovation requirements and policy options." Massachusetts Institute of Technology.

Finan, Ashley E., Francis "Chip" Cameron, Joseph R. Gray, David B. Matthews, and Edward G. Wallace. 2016. Enabling Nuclear Innovation: Strategies for Advanced Reactor Licensing. Nuclear Innovation Alliance.

GAO. 2015. "Nuclear Reactors Status and Challenges in Development and Deployment of New Commercial Concepts." United States Government Accountability Office Center for Science, Technology, and Engineering, Report to the Ranking Member, Subcommittee on Energy and Water Development, Committee on Appropriations, US Senate. 
GIF. 2011. Evaluation Methodology for Proliferation Resistance and Physical Protection of Generation IV Nuclear Energy Systems - Rev 6. Vol. GIF/PRPPWG/2011/003: GEN IV International Forum.

Gillespie, Christopher W, Robert A Johnson, Marty Martinez, and Emmanuel Taylor. 2016. "Innovation Pathway Study: US Commercial Nuclear Power."

Greenfield, Daniel, and John Kwoka. 2011. "The Cost Structure of Regional Transmission Organizations." The Energy Journal 32 (4). doi: 10.5547/ISSN0195-6574-EJ-Vol32-No4-8.

Gwartney, James D, Richard L Stroup, Russell S Sobel, and David A Macpherson. 2018. Economics: Private and Public Choice 16e. Boston, MA: Cengage Learning.

Hecht, Gabrielle. 2009. The radiance of France: Nuclear power and national identity after World War II: MIT press.

Helmuth, John A. 1988. "Nuclear Power Plant Capital Costs and Turnkey Estimates." The American Economist 32 (2):66-70.

Holl, Jack M, Roger M Anders, and Alice L Buck. 1986. United States Civilian Nuclear Power Policy, 1954-1984: A Summary History. USDOE Assistant Secretary for Management and Administration, Washington, DC ....

IAEA. 2011. Workforce Planning for New Nuclear Power Programmes: International Atomic Energy Agency.

IAEA. 2020. PRIS-Reactor Status Reports - Operational \& Long-Term Shutdown - By Country.

Jewell, Jessica. 2011. "Ready for nuclear energy?: An assessment of capacities and motivations for launching new national nuclear power programs." Energy Policy 39 (3):1041-1055. doi: 10.1016/j.enpol.2010.10.041.

Joskow, Paul L. 1974. "Inflation and environmental concern: Structural change in the process of public utility price regulation." The Journal of Law and Economics 17 (2):291-327.

Judy, S. 2013. "Builders of Vogtle Nuclear Plant Face Growing Costs, Concerns." ENR Southeast, August 21, 2013.

Kahan, Dan M, Hank Jenkins-Smith, and Donald Braman. 2011. "Cultural cognition of scientific consensus." Journal of risk research 14 (2):147-174.

Kim, Linsu. 1997. Imitation to innovation: The dynamics of Korea's technological learning: Harvard business press.

King, KJ, G Saiu, and H Kallio. 2001. "European passive plant (EP-1000) design status." ICONE-9: Proc. 9th Int. Conference on Nuclear Engineering.-Nice, France.

Krahn, S. 2017. Program on Technology Innovation: Government and Industry Roles in the Research, Development, Demonstration, and Deployment of Nuclear Reactors: Historical Review and Analysis. edited by Andrew Sowder. Palo Alto, CA: Electric Power Research Institute (EPRI).

MacDonald, Mott. 2010. "UK electricity generation costs update."

MacDonald, Mott. 2011. "Costs of low-carbon generation technologies." Report for the Committee on Climate Change. Brighton, Mott MacDonald.

Margaria, Chiara. 2019. "Learning and payoff externalities in an investment game." Games and Economic Behavior. doi: 10.1016/j.geb.2019.11.006.

Mari, Carlo. 2014. "The costs of generating electricity and the competitiveness of nuclear power." 
Progress in Nuclear Energy 73:153-161. doi: 10.1016/j.pnucene.2014.02.005.

Merrow, EW, SW Chapel, and C Worthing. 1979. A review of cost estimation in new technologies. RAND-2481-DOE, Santa Monica, CA.: RAND Corporation.

Merrow, EW, Kenneth E Phillips, and Christopher W Myers. 1981. Understanding cost growth and performance shortfalls in pioneer process plants. Rand Corp., Santa Monica, CA.

Metzler, Florian. 2012. "Global nuclear power supply chains and the rise of China's nuclear industry." Massachusetts Institute of Technology.

NRC. 2016. "NRC Vision and Strategy: Safely Achieving Effective and Efficient Non-Light Water Reactor Mission Readiness." ML16139A812 Draft Rev 1.

NRC. 2017a. NRC Non-Light Water Reactor Mid-Term and Long-Term Implementation Action Plans. Nuclear Regulatory Commission.

NRC. 2017b. NRC Non-Light Water Reactor Near-Term Implementation Action Plans. Nuclear Regulatory Commission.

NRG. 2011. "NRG Energy, Inc. Provides Greater Clarity on the South Texas Nuclear Development Project (STP 3\&4)." Business Wire, 19 April 2011. http://www.businesswire.com/news/home/20110419007026/en/NRG-Energy-Greater-ClaritySouth-Texas-Nuclear.

Pavey, R. 2012. "NRC Says Vogtle Rebar Differs from Approved Desings." The Augusta Chronicle, April 26, 2012.

Pineau, Pierre-Olivier, Hasina Rasata, and Georges Zaccour. 2011. "A dynamic oligopolistic electricity market with interdependent market segments." The Energy Journal 32 (4).

Power. 2009. CPS Energy Asks Court to Define STP Expansion Nuclear Pact. PowerMag. Accessed 18 August 2017.

Rangel, Lina Escobar, and François Lévêque. 2015. "Revisiting the cost escalation curse of nuclear power: New lessons from the french experience." Economics of Energy \& Environmental Policy $4(2)$.

Reinhart, RJ. 2019. "40 Years After Three Mile Island, Americans Split on Nuclear Power." Gallup. https://news.gallup.com/poll/248048/years-three-mile-island-americans-split-nuclear-power.aspx.

Ruuska, Inkeri, Tuomas Ahola, Karlos Artto, Giorgio Locatelli, and Mauro Mancini. 2011. "A new governance approach for multi-firm projects: Lessons from Olkiluoto 3 and Flamanville 3 nuclear power plant projects." International Journal of Project Management 29 (6):647-660.

Samanta, Pranab. 2019. NRC Regulatory History of Non-Light Water Reactors (1950-2019). Brookhaven National Lab.(BNL), Upton, NY (United States).

Samanta, Pranab. 2020. Regulatory Review of Micro-Reactors-Initial Considerations. Brookhaven National Lab.(BNL), Upton, NY (United States).

Schimmoller, Brian. 2008. "Lost in the zeroes." Power Engineering 112 (1):14-15.

Souder, Elizabeth. 2010. "NRG Energy, CPS Energy settle dispute over funding for new nuclear reactors." The Dallas Morning News, February. https://www.dallasnews.com/business/business/2010/02/17/NRG-Energy-CPS-Energy-settle$\underline{3337}$.

Sovacool, Benjamin K, and Christopher Cooper. 2008. "Nuclear nonsense: Why nuclear power is no 
answer to climate change and the world's post-Kyoto energy challenges." Wm. \& Mary Envtl. L. \& Pol'y Rev. 33:1.

Sovacool, Benjamin K, Alex Gilbert, and Daniel Nugent. 2014. "Risk, innovation, electricity infrastructure and construction cost overruns: Testing six hypotheses." Energy 74:906-917. doi: 10.1016/j.energy.2014.07.070.

Starr, Chauncey. 1969. "Social benefit versus technological risk." Science:1232-1238.

Sterman, John D 2000. Business dynamics: systems thinking and modeling for a complex world. Boston, MA: Irwin McGraw-Hill.

Sunstein, Cass R. 2002. "Probability neglect: Emotions, worst cases, and law." The Yale Law Journal $112(1): 61-107$.

Szilard, Ronaldo, Phil Sharpe, Edward Kee, Edward Davis, and Eugene Grecheck. 2016. Economic and Market Challenges Facing the US Nuclear Commercial Fleet. Idaho Falls, ID (United States): Idaho National Lab.(INL).

Taylor, John J. 1989. "Improved and safer nuclear power." Science 244 (4902):318-325.

Thurner, Paul W, Laura Mittermeier, and Helmut Küchenhoff. 2014. "How long does it take to build a nuclear power plant? A non-parametric event history approach with P-splines." Energy Policy 70:163-171.

Torraco, Richard J. 2005. "Writing integrative literature reviews: Guidelines and examples." Human resource development review 4 (3):356-367.

Turek, Michael Gerald. 1995. "System dynamics analysis of financial factors in nuclear power plant operations." Massachusetts Institute of Technology.

US AEC. 1974. Nuclear Power Growth, 1974-2000 Volume 7 (WASH 1139). Edited by Office of Planning and Analysis, WASH-1139: US Atomic Energy Commission.

van de Graaff, Shashi. 2016. "Understanding the nuclear controversy: An application of cultural theory." Energy Policy 97:50-59. doi: 10.1016/j.enpol.2016.07.007.

Verma, Aditi. 2012. "Manpower development for new nuclear energy programs." Massachusetts Institute of Technology.

Wearne, SH, and RH Bird. 2009. "UK Experience of Consortia Engineering for Nuclear Power Stations." School of Mechanical, Aerospace \& Civil Engineering, University of Manchester, Dalton Nuclear Institute.

WNA. 2017a. "The Economics of Nuclear Power." http://www.world-nuclear.org/informationlibrary/economic-aspects/economics-of-nuclear-power.aspx.

WNA. 2017b. Nuclear Power Economics and Project Structuring. World Nuclear Association.

WNA. 2020. "Financing Nuclear Energy." World Nuclear Association, accessed 5/13/2020. https://www.world-nuclear.org/information-library/economic-aspects/financing-nuclearenergy.aspx.

Wright, Erik R., Kyuman Cho, and Makarand Hastak. 2014. "Assessment of Critical Construction Engineering and Management Aspects of Nuclear Power Projects." Journal of Management in Engineering 30 (4):04014016. doi: doi:10.1061/(ASCE)ME.1943-5479.0000286.

Zimmerman, Martin B. 1982. "Learning effects and the commercialization of new energy technologies: The case of nuclear power." The Bell Journal of Economics:297-310. 


\section{Retrospective analysis of LWR technology: lessons for today}

May 15,2020

xliii

\section{Appendix - Bibliography of reviewed works}

Adomaitis, Dennis, Gianfranco Saiu, and Mariano Oyarzabal. 1998. "European passive plant program: A design for the 21 st century." Nuclear engineering and design 179 (1):17-29.

AEC. 1962. Civilian nuclear power: A report to the president, 1962.

AEC. 1967. "Civilian Nuclear Power-The 1967 Supplement to the 1962 Report to the President." US Congress, Joint Committee on Atomic Energy, Nuclear Power Economics.

AEC. 1974. Power plant capital costs, current trends and sensitivity to economic parameters. Vol. 7: AEC.

Ahearne, John F. 2011. "Prospects for nuclear energy." Energy Economics 33 (4):572-580.

Amsden, Alice Hoffenberg. 1992. Asia's next giant: South Korea and late industrialization: Oxford University Press on Demand.

Anadon, L. D., V. Bosetti, M. Bunn, M. Catenacci, and A. Lee. 2012. "Expert judgments about RD\&D and the future of nuclear energy." Environ Sci Technol 46 (21):11497-504. doi: $10.1021 / \mathrm{es} 300612 \mathrm{c}$.

Anadon, Laura Diaz, Gabriel Chan, Amitai Y. Bin-Nun, and Venkatesh Narayanamurti. 2016. "The pressing energy innovation challenge of the US National Laboratories." Nature Energy 1 (10). doi: 10.1038/nenergy.2016.117.

Antal, Miklós. 2020. "A "parasite market": A competitive market of energy price comparison websites reduces consumer welfare." Energy Policy. doi: 10.1016/j.enpol.2019.111228.

Arrow, KJ. 1971. "The Economic Implications of Learning by Doing." The Review of Economic Studies 29 (3):155-173

Arthur, W Brian. 1983. "On competing technologies and historical small events: the dynamics of choice under increasing returns."

Arthur, W Brian. 1988. "Competing technologies: an overview. G. Dosi, C." Technical Change and Economic Theory. London: Pinter:590-607.

Arthur, W Brian. 1989. "Competing technologies, increasing returns, and lock-in by historical events." The economic journal 99 (394):116-131.

Averch, Harvey, and Leland L Johnson. 1962. "Behavior of the firm under regulatory constraint." The American Economic Review 52 (5):1052-1069.

Behling, Noriko, Mark C. Williams, and Shunsuke Managi. 2019. "Regulating Japan's nuclear power industry to achieve zero-accidents." Energy Policy 127:308-319. doi: 10.1016/j.enpol.2018.11.052.

Berndt, Eric, and Daniel P. Aldrich. 2016. "Power to the people or regulatory ratcheting? Explaining the success (or failure) of attempts to site commercial US nuclear power plants: 1954-1996." International Journal of Energy Research 40 (7):903-923. doi: 10.1002/er.3475.

Bird, Raymond, and Stephen Wearne. 2017. "Contract structure for nuclear power projects." Proceedings of the Institution of Civil Engineers - Management, Procurement and Law 170 (3):131-137. doi: 10.1680/jmapl.16.00042.

Bisconti, Ann Stouffer. 2018. "Changing public attitudes toward nuclear energy." Progress in Nuclear Energy 102:103-113. doi: 10.1016/j.pnucene.2017.07.002. 
Bistline, J., and R. James. 2018. Exploring the Role of Advanced Nuclear in Future Energy Markets: Economic Drivers, Barriers, and Impacts in the United States. Palo Alto, CA: Electric Power Research Insitute. (EPRI).

Bistline, John E. T., and Geoffrey J. Blanford. 2020. "Value of technology in the U.S. electric power sector: Impacts of full portfolios and technological change on the costs of meeting decarbonization goals." Energy Economics. doi: 10.1016/j.eneco.2020.104694.

Bistline, John, Revis James, and Andrew Sowder. 2019. "Technology, Policy, and Market Drivers of (and Barriers to) Advanced Nuclear Reactor Deployment in the United States After 2030." Nuclear Technology:1-20.

Buck, Alice L. 1983. A history of the atomic energy commission. USDOE Assistant Secretary for Management and Administration, Washington, DC ....

Budnitz, Robert J. 2016. "Nuclear power: Status report and future prospects." Energy Policy 96:735-739. doi: 10.1016/j.enpol.2016.03.011.

Burness, H Stuart, W David Montgomery, and James P Quirk. 1980a. "Capital contracting and the regulated firm." The American Economic Review 70 (3):342-354.

Burness, H Stuart, W David Montgomery, and James P Quirk. 1980b. "The turnkey era in nuclear power." Land Economics 56 (2):188-202.

Cheng, Lap-Yan. 2019. The GIF Proliferation Resistance and Physical Proection Methodology Applied to GEN IV System Designs: An Update. Brookhaven National Lab.(BNL), Upton, NY (United States).

CleanAir. 2018. Advanced Nuclear Energy Need, Characteristics, Projected Costs, and Opportunities. Boston, MA: Clean Air Task Force.

Cleary, Kathryne, and Karen Palmer. 2020. "US Electricity Markets 101." Resources for the Future. https://www.rff.org/publications/explainers/us-electricity-markets-101/.

Cohen, Linda R, and Roger G Noll. 1983. "The Political Economy of Government Programs to Promote New Technology."

Cojazzi, Giacomo G, Lap-Yan Cheng, and G. Renda. 2018. "The GIF Proliferation Resistance and Physical Protection Methodology Applied to Gen IV System Designs: Some Reflections."

Collins, John, and Charles Mason. 2016. Summit on Improving the Economics of America's Nuclear Power Plants. Idaho Falls, ID (United States): Idaho National Laboratory (INL).

Cowan, Robin. 1990. "Nuclear power reactors: a study in technological lock-in." The journal of economic history 50 (3):541-567.

Csereklyei, Zsuzsanna. 2014. "Measuring the impact of nuclear accidents on energy policy." Ecological Economics 99:121-129.

Dato, Prudence, Tunç Durmaz, and Aude Pommeret. 2019. "Smart Grids and Renewable Electricity Generation by Households." Energy Economics. doi: 10.1016/j.eneco.2019.104511.

David, Paul A, and Julie Ann Bunn. 1988. "The economics of gateway technologies and network evolution: Lessons from electricity supply history." Information economics and policy 3 (2):165202.

Davis, Lucas, and Catherine Hausman. 2014. The value of transmission in electricity markets: Evidence from a nuclear power plant closure. National Bureau of Economic Research. 


\section{Retrospective analysis of LWR technology: lessons for today}

May 15,2020

Davis, Lucas, and Catherine Hausman. 2016. "Market Impacts of a Nuclear Power Plant Closure." American Economic Journal: Applied Economics 8 (2):92-122. doi: 10.1257/app.20140473.

Davis, Lucas W. 2012. "Prospects for Nuclear Power." Journal of Economic Perspectives 26 (1):49-66. doi: $10.1257 /$ jep.26.1.49.

De la Torre, Joseba, and Maria del Mar Rubio-Varas. 2018. "Learning by Doing: The First Spanish Nuclear Plant." Business History Review 92 (1):29-55. doi: 10.1017/s0007680518000053.

De Meio Reggiani, Martin C., Miguel Vazquez, Michelle Hallack, and Nélida B. Brignole. 2019. "The role of governmental commitment on regulated utilities." Energy Economics. doi: 10.1016/j.eneco.2019.104518.

Deutch, John, Michael Greenstone, Shirley Jackson, William Madia, Richard Meserve, Dan Reicher, Joy Rempe, Gary Samore, Clay Sell, Phil Sharp, Steve Specker, and Joe Turnage. 2016. Secretary of Energy Advisory Board Report of the Task Force on the Future of Nuclear Power.

Di Nucci, Maria Rosaria. 2019. "From Military to Early Civilian Applications." In The Technological and Economic Future of Nuclear Power, 7-34.

Di Stefano, Giada, Alfonso Gambardella, and Gianmario Verona. 2012. "Technology push and demand pull perspectives in innovation studies: Current findings and future research directions." Research Policy 41 (8):1283-1295. doi: 10.1016/j.respol.2012.03.021.

Djelic, Marie-Laure, and Sigrid Quack. 2007. "Overcoming path dependency: path generation in open systems." Theory and Society 36 (2):161-186. doi: 10.1007/s11186-007-9026-0.

DOE-NE. 1980. US Central Station Nuclear Electric Generating Units: significant milestones. United States: US Department of Energy.

Dubin, Jeffrey A, and Geoffrey S Rothwell. 1989. "Risk and reactor safety systems adoption." Journal of Econometrics 42 (2):201-218.

Dubin, Jeffrey A., and Geoffrey S. Rothwell. 1990. "Subsidy to Nuclear Power through Price-Anderson Liability Limit." Contemporary Economic Policy 8 (3):73-79. doi: 10.1111/j.14657287.1990.tb00645.x.

Energy, US DOE Office of Nuclear. 2010. Next Generation Nuclear Plant Report to Congress. US DOE Washington, DC.

Finan, Ashley. 2012. "Energy system transformation: an evaluation of innovation requirements and policy options." Massachusetts Institute of Technology.

Finan, Ashley E., Francis "Chip" Cameron, Joseph R. Gray, David B. Matthews, and Edward G. Wallace. 2016. Enabling Nuclear Innovation: Strategies for Advanced Reactor Licensing. Nuclear Innovation Alliance.

GAO. 2015. "Nuclear Reactors Status and Challenges in Development and Deployment of New Commercial Concepts." United States Government Accountability Office Center for Science, Technology, and Engineering, Report to the Ranking Member, Subcommittee on Energy and Water Development, Committee on Appropriations, US Senate.

Geist, Edward. 2015. Overcoming Obstacles to Advanced Reactor Technologies: RAND Corporation.

GIF. 2011. Evaluation Methodology for Proliferation Resistance and Physical Protection of Generation IV Nuclear Energy Systems - Rev 6. Vol. GIF/PRPPWG/2011/003: GEN IV International Forum.

Gillespie, Christopher W, Robert A Johnson, Marty Martinez, and Emmanuel Taylor. 2016. "Innovation 
Pathway Study: US Commercial Nuclear Power."

Grandy, Christopher, James J Sienicki, Anton Moisseytsev, Lubomir Krajtl, Mitchell T Farmer, Taek K Kim, and B Middleton. 2014. Advanced Fast Reactor-100 (AFR-100) Report for the Technical Review Panel. Argonne National Lab.(ANL), Argonne, IL (United States).

Grape, Sophie, Staffan Jacobsson Svärd, Carl Hellesen, Peter Jansson, and Matilda Åberg Lindell. 2014. "New perspectives on nuclear power - Generation IV nuclear energy systems to strengthen nuclear non-proliferation and support nuclear disarmament." Energy Policy 73:815-819. doi: 10.1016/j.enpol.2014.06.026.

Greenfield, Daniel, and John Kwoka. 2011. "The Cost Structure of Regional Transmission Organizations." The Energy Journal 32 (4). doi: 10.5547/ISSN0195-6574-EJ-Vol32-No4-8.

Haas, Reinhard, Lutz Mez, and Amela Ajanovic. 2019. The Technological and Economic Future of Nuclear Power: Springer.

Harding, Jim. 1990. "Reactor Safety and Risk Issues." Contemporary Economic Policy 8 (3):94-105.

Hazir, Oncu, and Gunduz Ulusoy. 2019. "A Classification and Review of Approaches and Methods for Modeling Uncertainty in Projects." International Journal of Production Economics. doi: 10.1016/j.ijpe.2019.107522.

Hecht, Gabrielle. 1996. "Rebels and pioneers: technocratic ideologies and social identities in the French nuclear workplace, 1955-69." Social studies of science 26 (3):483-530.

Hecht, Gabrielle. 2009. The radiance of France: Nuclear power and national identity after World War II: MIT press.

Heffron, Raphael J. 2013. "Nuclear energy policy in the United States 1990-2010: A federal or state responsibility?" Energy Policy 62:254-266.

Helmuth, John A. 1988. "Nuclear Power Plant Capital Costs and Turnkey Estimates." The American Economist 32 (2):66-70.

Hesamzadeh, M. R., D. R. Biggar, D. W. Bunn, and E. Moiseeva. 2020. "The Impact of Generator Market Power on the Electricity Hedge Market." Energy Economics. doi: 10.1016/j.eneco.2019.104649.

Hewlett, Richard Greening, Richard G Hewlett, and Jack M Holl. 1989. Atoms for peace and war, 19531961: Eisenhower and the Atomic Energy Commission. Vol. 3: Univ of California Press.

Hill, Douglas. 1983. Effect of scale and quantity on the cost and performance of energy technologies: a literature review. Brookhaven National Lab.

Holl, Jack M, Roger M Anders, and Alice L Buck. 1986. United States Civilian Nuclear Power Policy, 1954-1984: A Summary History. USDOE Assistant Secretary for Management and Administration, Washington, DC ....

IAEA. 2011. Workforce Planning for New Nuclear Power Programmes: International Atomic Energy Agency.

Jha, Akshaya. 2014. Regulatory Induced Risk Aversion in Procurement Behavior: An Empirical Analysis of US Investor-Owned Electric Utilities From 1987-1998. Stanford, CA: Stanford University.

Joskow, Paul L. 1974. "Inflation and environmental concern: Structural change in the process of public utility price regulation." The Journal of Law and Economics 17 (2):291-327.

Joskow, Paul L, and John E Parsons. 2009. "The economic future of nuclear power." Daedalus 138 (4):45-59. 


\section{Retrospective analysis of LWR technology: lessons for today}

May 15,2020

xIvii

Joskow, Paul L. 2019. "Challenges for wholesale electricity markets with intermittent renewable generation at scale: the US experience." Oxford Review of Economic Policy 35 (2):291-331. doi: 10.1093/oxrep/grz001.

Joskow, Paul L., and John E. Parsons. 2012. "The Future of Nuclear Power After Fukushima." Economics of Energy \& Environmental Policy 1 (2). doi: 10.5547/2160-5890.1.2.7.

Kahan, Dan M, Hank Jenkins-Smith, and Donald Braman. 2011. "Cultural cognition of scientific consensus." Journal of risk research 14 (2):147-174.

Karlson, Stephen H. 1986. "Adoption of competing inventions by United States steel producers." The Review of Economics and Statistics:415-422.

Kim, Lance Kyungwoo. 2011. "Long-Term Planning for Nuclear Energy Systems Under Deep Uncertainty." UC Berkeley.

Kim, Linsu. 1997. Imitation to innovation: The dynamics of Korea's technological learning: Harvard business press.

King, KJ, G Saiu, and H Kallio. 2001. "European passive plant (EP-1000) design status." ICONE-9: Proc. 9th Int. Conference on Nuclear Engineering.-Nice, France.

Krahn, S. 2017. Program on Technology Innovation: Government and Industry Roles in the Research, Development, Demonstration, and Deployment of Nuclear Reactors: Historical Review and Analysis. edited by Andrew Sowder. Palo Alto, CA: Electric Power Research Institute (EPRI).

Law, Stephen M. 2014. "Assessing the Averch-Johnson-Wellisz Effect for Regulated Utilities." International Journal of Economics and Finance 6 (8). doi: 10.5539/ijef.v6n8p41.

Lester, Richard K. 2016. "A Roadmap for US Nuclear Energy Innovation." Issues in Science and Technology 32 (2).

Lester, Richard K, and David M Hart. 2011a. Unlocking energy innovation: How America can build a low-cost, low-carbon energy system: MIT Press.

Lester, Richard K., and David M Hart. 2011b. Unlocking Energy Innovation: How America Can Build a Low-Cost, Low-Carbon Energy System, Unlocking Energy Innovation: How America Can Build a Low-Cost, Low-Carbon Energy System

MIT Press.

Levendis, John, Walter Block, and Joseph Morrel. 2006. "Nuclear Power." Journal of Business Ethics 67 (1):37-49. doi: 10.1007/s10551-006-9003-y.

Linares, Pedro, and Adela Conchado. 2013. "The economics of new nuclear power plants in liberalized electricity markets." Energy Economics 40:S119-S125. doi: 10.1016/j.eneco.2013.09.007.

Margaria, Chiara. 2019. "Learning and payoff externalities in an investment game." Games and Economic Behavior. doi: 10.1016/j.geb.2019.11.006.

Metzler, Florian. 2012. "Global nuclear power supply chains and the rise of China's nuclear industry." Massachusetts Institute of Technology.

Mohamed Haikel, Khalfallah. 2011. "A Game Theoretic Model for Generation Capacity Adequacy: Comparison Between Investment Incentive Mechanisms in Electricity Markets." The Energy Journal 32 (4). doi: 10.5547/ISSN0195-6574-EJ-Vol32-No4-7.

Montgomery, W David, and James P Quirk. 1978. "Cost escalation in nuclear power." 
Mooz, William E. 1980. Cost analysis of light water reactor power plants. RAND CORP SANTA MONICA CA.

Mooz, William E. 1979. A Second Cost Analysis of Light Water Reactor Power Plants. Vol. R-2594-RC. Santa Monica, CA: RAND Corporation.

Nelson, R.R, ed. 1993. Technical Innovation and National Systems, National Innovation Systems: a comparative analysis: Oxford University Press on Demand.

NRC. 2016. "NRC Vision and Strategy: Safely Achieving Effective and Efficient Non-Light Water Reactor Mission Readiness." ML16139A812 Draft Rev 1.

NRC. 2017. NRC Non-Light Water Reactor Near-Term Implementation Action Plans. Nuclear Regulatory Commission.

O’Brien, Cheryl C. 2018. "Is bad performance the answer to saving the nuclear power industry?" The Electricity Journal. doi: https://doi.org/10.1016/j.tej.2018.11.002.

Pineau, Pierre-Olivier, Hasina Rasata, and Georges Zaccour. 2011. "A dynamic oligopolistic electricity market with interdependent market segments." The Energy Journal 32 (4).

Pretel, David, and Lino Camprubí. 2018. "Corrections to: Technology and Globalisation." In Technology and Globalisation, E1-E1.

Quintana-Rojo, Consolación, Fernando-Evaristo Callejas-Albiñana, Miguel-Ángel Tarancón, and Pablo del Río. 2020. "Assessing the feasibility of deployment policies in wind energy systems. A sensitivity analysis on a multiequational econometric framework." Energy Economics. doi: 10.1016/j.eneco.2020.104688.

Quirk, James, and Katsuaki Terasawa. 1986. "Sample selection and cost underestimation bias in pioneer projects." Land Economics 62 (2):192-200.

Reinhart, RJ. 2019. "40 Years After Three Mile Island, Americans Split on Nuclear Power." Gallup. https://news.gallup.com/poll/248048/years-three-mile-island-americans-split-nuclear-power.aspx.

Rhine, Russell. 2001. "Economies of scale and optimal capital in nuclear and fossil fuel electricity production." Atlantic Economic Journal 29 (2):203-214.

Roche, B. 2001. "The European utility requirement document (EUR)." Nuclear engineering and design 209 (1-3):39-45.

Rubio-Varas, M. d Mar, and Joseba De la Torre. 2017. "How did Spain Become the Major US Nuclear Client?" In The Economic History of Nuclear Energy in Spain, 119-153.

Samanta, Pranab. 2019. NRC Regulatory History of Non-Light Water Reactors (1950-2019). Brookhaven National Lab.(BNL), Upton, NY (United States).

Samanta, Pranab. 2020. Regulatory Review of Micro-Reactors-Initial Considerations. Brookhaven National Lab.(BNL), Upton, NY (United States).

Schmalensee, Richard. 1980. "Appropriate government policy toward commercialization of new energy supply technologies." The Energy Journal 1 (2).

SMRSTART. 2017. The Economics of Small Modular Reactors.

Sovacool, Benjamin K., Mari Martiskainen, Andrew Hook, and Lucy Baker. 2020. "Beyond cost and carbon: The multidimensional co-benefits of low carbon transitions in Europe." Ecological Economics 169. doi: 10.1016/j.ecolecon.2019.106529. 


\section{Retrospective analysis of LWR technology: lessons for today}

May 15,2020

xlix

Sowder, Andrew. 2018. "Government and Industry Roles in Commercialization of Nuclear Power: Lessons from the First Round." 4th Gen IV International Forum Symposium.

Starr, Chauncey. 1969. "Social benefit versus technological risk." Science:1232-1238.

Sunstein, Cass R. 2002. "Probability neglect: Emotions, worst cases, and law." The Yale Law Journal $112(1): 61-107$.

Szilard, Ronaldo, Phil Sharpe, Tammie Borders, Edward Kee, Edward Davis, and Eugene Grecheck. 2017. Economic and Market Challenges Facing the US Nuclear Commercial Fleet -- Cost and Revenue Study. Idaho Falls, ID (United States): Idaho National Lab.(INL).

Szilard, Ronaldo, Phil Sharpe, Edward Kee, Edward Davis, and Eugene Grecheck. 2016. Economic and Market Challenges Facing the US Nuclear Commercial Fleet. Idaho Falls, ID (United States): Idaho National Lab.(INL).

Taylor, John J. 1989. "Improved and safer nuclear power." Science 244 (4902):318-325.

Torraco, Richard J. 2005. "Writing integrative literature reviews: Guidelines and examples." Human resource development review 4 (3):356-367.

Turinsky, Paul J. 2018. "Preface to Shippingport Atomic Power Station thematic issue." Progress in Nuclear Energy 102:1-8. doi: 10.1016/j.pnucene.2017.03.030.

van de Graaff, Shashi. 2016. "Understanding the nuclear controversy: An application of cultural theory." Energy Policy 97:50-59. doi: 10.1016/j.enpol.2016.07.007.

Verma, Aditi. 2012. "Manpower development for new nuclear energy programs." Massachusetts Institute of Technology.

Walker, JS, and TR Wellock. 2010. "A Short History of Nuclear Regulation, 1946-2009: US Nuclear Regulatory Commission: https://www. nrc. gov/docs/ML1029." ML102980443. pdf.

Wealer, Ben, Simon Bauer, Nicolas Landry, Hannah Seiß, and Christian R von Hirschhausen. 2018. Nuclear power reactors worldwide: Technology developments, diffusion patterns, and country-bycountry analysis of implementation (1951-2017). DIW Data Documentation.

Wearne, SH, and RH Bird. 2009. "UK Experience of Consortia Engineering for Nuclear Power Stations." School of Mechanical, Aerospace \& Civil Engineering, University of Manchester, Dalton Nuclear Institute.

Yang, Chi-Jen. 2008. Powered by technology or powering technology?-Belief-based decision-making in nuclear power and synthetic fuel: Princeton University.

Zimmerman, Martin B. 1982. "Learning effects and the commercialization of new energy technologies: The case of nuclear power." The Bell Journal of Economics:297-310. 